Universidad de Lima

Facultad de Comunicación

Carrera de Comunicación

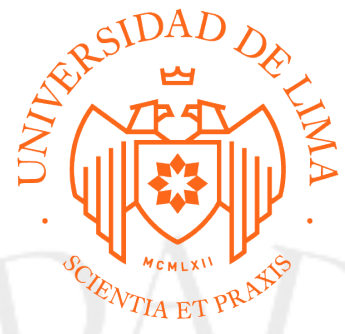

\title{
LOS QUE QUEDAN
}

Trabajo de Suficiencia Profesional para optar el Título Profesional de Licenciado en Comunicación

\section{Karla Alejandra Gomez Loayza}

Código 20140566

\section{Asesor: Ricardo Bedoya}

Lima - Perú

Enero de 2020 


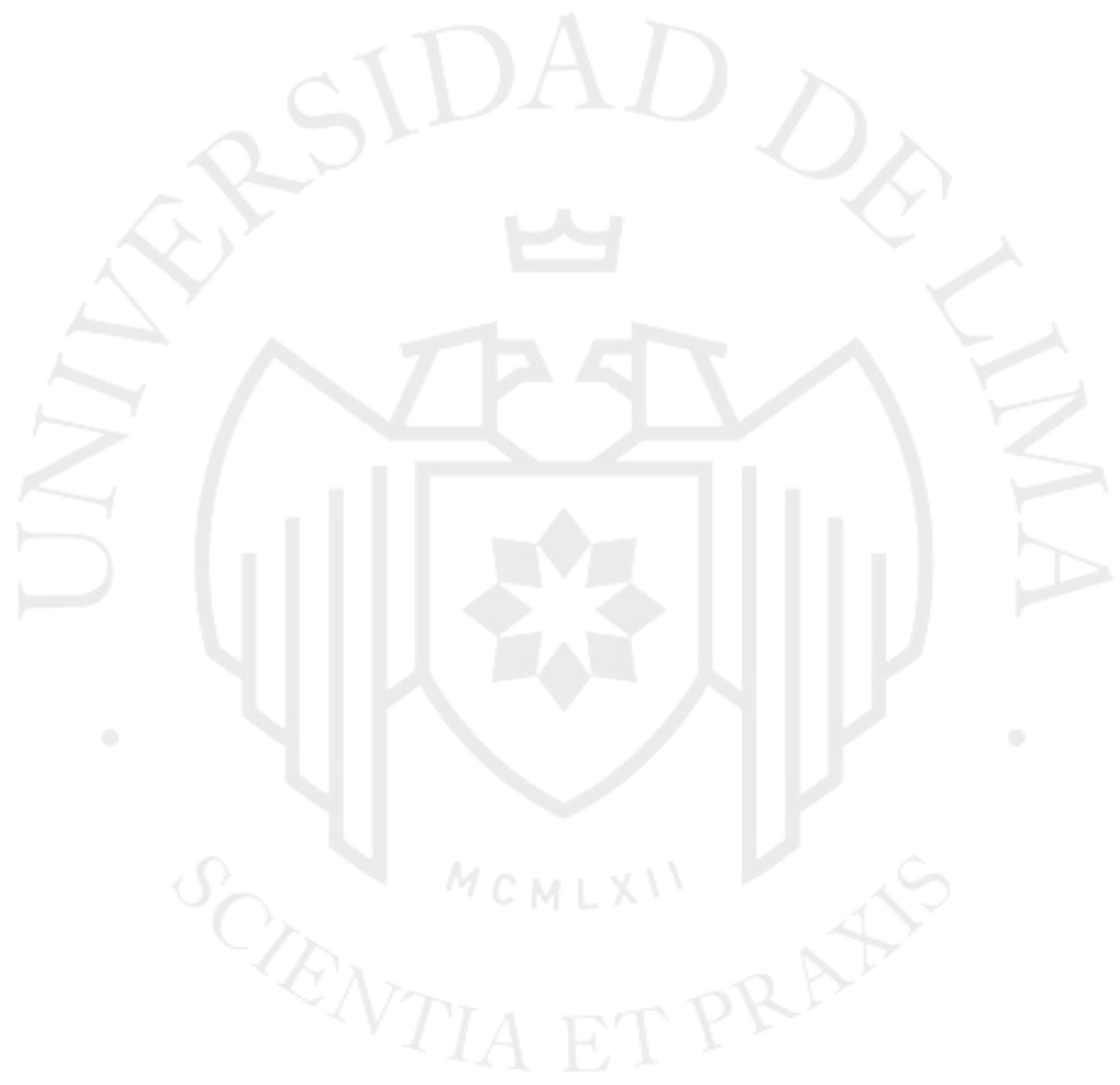




\section{LOS QUE QUEDAN}




\section{ÍNDICE}

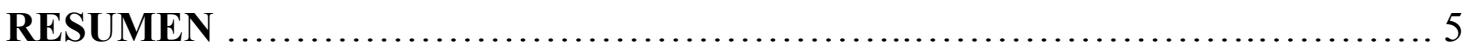

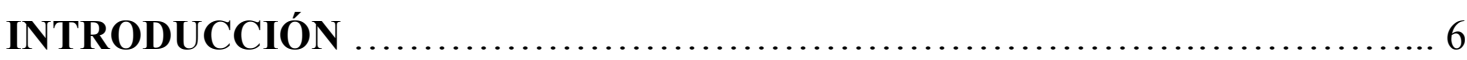

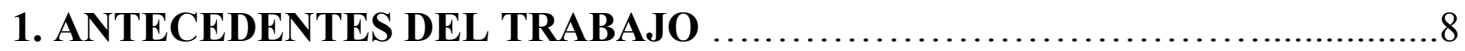

1.1 Antecedentes personales de la directora $\ldots \ldots \ldots \ldots \ldots \ldots \ldots \ldots \ldots \ldots \ldots . . . \ldots$

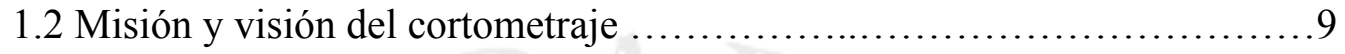

1.3 Contexto y antecedentes audiovisuales ........................... 10

1.4 Objetivos ...................................................... 12

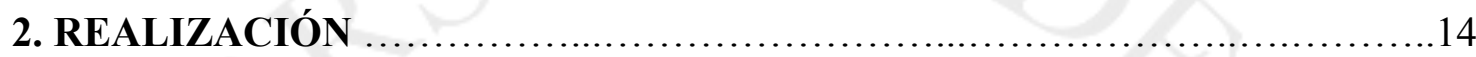

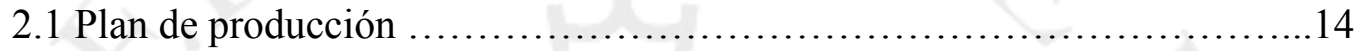

2.1.1 Subfase previa (creativa) .................................14

2.2 Descripción del trabajo de preproducción ..............................15

2.2.1 Elaboración del guion.....................................15

2.2.2 Elección del casting.........................................17

2.2.3 Elección del equipo técnico................................18

2.2.4 Preproducción de las distintas áreas.........................21

2.3 Descripción del trabajo de grabación..................................28

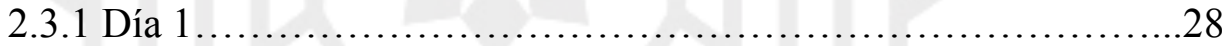

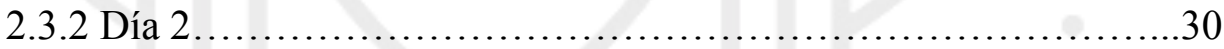

2.4 Descripción del trabajo de postproducción..............................31

2.4.1 Edición de imagen..........................................31

2.4 .2 Colorización................................................ 31

2.4.3 Diseño sonoro y musicalización.............................32

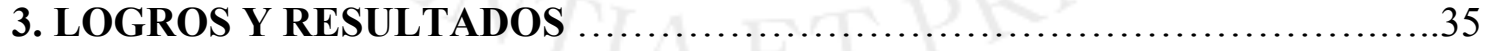

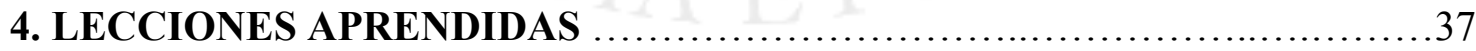

4.1 Planeamiento .......................................................... 37

4.2 Conclusiones .........................................................

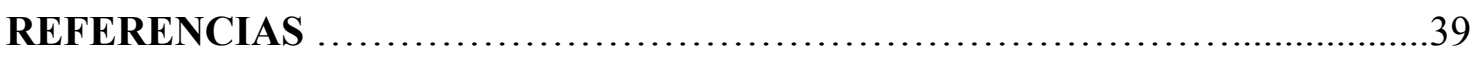

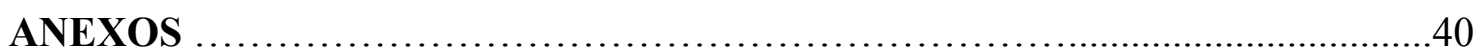




\section{RESUMEN}

El presente trabajo de suficiencia profesional describe el proceso de realización del cortometraje Los que quedan, desde la concepción del guion, la ejecución del rodaje, el proceso de postproducción hasta la estrategia de distribución.

Los que quedan nace a partir de la idea del olvido e ingratitud hacia nuestros familiares o amistades mayores. Este cortometraje busca dar vida a una experiencia muy común en personas ya ancianas, que quizá no se visibilice y no sea percibida del todo. La historia no solo busca conmover, sino también concientizar y representar. La vejez es una etapa inevitable de la vida, por lo que se toca un tema muy humano y universal: la soledad y la espera de la muerte inminente.

Ante la importancia de transmitir este mensaje, se ha realizado un análisis que será presentado en este trabajo. En primer lugar, explicaré la razón por la que se eligió tocar el tema y por qué un cortometraje era la mejor forma de hacerlo. En segundo lugar, se explicará lo que fue el proceso creativo desde el surgimiento de la idea inicial hasta la elaboración del guion en sí. Por último, se detallará el trabajo que implicó la realización de este cortometraje, desde su preproducción hasta la postproducción. 


\section{INTRODUCCIÓN}

Graciela es una persona ya mayor, que no ve a sus hijos hace mucho tiempo. Pasa sus días en cama por órdenes de su médico y hace cinco años sus hijos le contrataron una empleada personal, con la que comparte la gran parte de su tiempo. Ella se llama Isabela, pero durante todo el cortometraje la conocemos como 'Chabelita'. Ambas forman una linda amistad. Una tarde, ya un tanto cansada de su vida en los últimos días, Graciela le pide a Chabela que le ayude a fingir su muerte para darles una lección a sus hijos. Al principio parece ser solo una idea; sin embargo, durante el corto se pondrá en duda si todo era parte de un juego o verdaderamente Graciela falleció.

Los que quedan nace a partir de la idea del olvido e ingratitud hacia nuestros familiares o amistades mayores. Por lo mismo, no será difícil que la historia genere empatía rápidamente con un público en general. Al ser una historia familiar puede ser vista, disfrutada y entendida por niños (7 años) hasta adultos y ancianos. Está dirigido a familias nucleares, monoparentales o personas que viven solas; porque desde cualquier situación, siempre habrá espectadores que sean nietos, hijos, padres o abuelos.

Entonces, cabe preguntarnos: ¿qué tan buenos somos con nuestros familiares mayores? Espero que esta historia, al menos, inspire a uno de los espectadores de la sala a que llamen a sus padres o abuelos y les pregunten “¿cómo están?”. Y no esperar a que estén muertos para que recién se conviertan en nuestra prioridad.

Asimismo, el cortometraje busca dar una lección de vida: el tiempo compartido vale mucho más que cualquier otro vínculo familiar, o de sangre.

Para que esta historia logre el impacto esperado, se trabajó con un despliegue actoral de renombre. El personaje principal está protagonizado por la actriz ícono del cine peruano: Delfina Paredes, que cuenta con una gran trayectoria dentro de la industria. Ella, como protagonista principal, le dará vida a la historia. Además, actrices como Úrsula Mármol, Natalia Cárdenas, Caroll Chiara y el actor Oscar Beltrán gozan de reconocimiento dentro de las producciones audiovisuales. 
La historia de por sí es original e innovadora, contiene diálogos frescos y emotivos, lo que permite que el espectador no deje de estar enganchado en ningún momento, y el final abierto nos deja con la sensación de preguntarnos “¿qué es lo que realmente sucedió? ¿Graciela murió de verdad o es que fingió su muerte?”. Lo que abre un diálogo entre los espectadores después de ver el cortometraje. La narrativa engaña constantemente al espectador, y los giros de la historia sorprenden hasta el plano final. Lo que lo convierte en una historia sentimental, sin caer en la cursilería.

Por último, la historia se apoya con una propuesta audiovisual técnicamente correcta; lograda a través de un buen rodaje, sin contratiempos y a un nivel máximo de organización. 


\section{ANTECEDENTES DEL TRABAJO}

\subsection{Antecedentes personales de la directora}

Desde muy pequeña he tenido estas inmensas ganas de cambiar el mudo a través de las historias que escribía. Sentía que un cuento bien contado podría ser la herramienta más poderosa para sanar heridas, liberar recuerdos tristes y alegrar el alma. Mi mamá me repetía constantemente: "Sé la voz de aquellos que no pudieron hablar". Entonces, crecí de esa manera, sabiendo que tenía una gran responsabilidad en mis manos.

Fue entonces que durante mi último año en la universidad se me presentó la oportunidad de escribir una historia y dirigirla. Sin condiciones, con total libertad en la escritura y en la realización. Por fin, algo que sería completamente mío. Sabía que esa oportunidad no la podía desaprovechar.

En aquel primer guion, decidí hablar sobre un artista frustrado, con problemas existenciales y con un arte increíble que no sabía aprovechar. Era yo reflejada en el artista. Era yo en mis frustraciones, crisis y el haberme desconectado con lo esencial: saber quién soy y qué quiero para mi vida.

Sin embargo, me alejé de lo que siempre había querido ser: la voz de los que no pueden hablar; y esta idea, un tanto pretenciosa y exagerada, solo era mi voz hablando de mí misma.

El tiempo pasó.

Mi abuela falleció un 28 de febrero del 2019. Éramos muy unidas. Vivía muy lejos de mi casa, pero el amor era (y es) tan grande, que acortaba cualquier distancia. Hablar con ella era disfrutar de conversaciones increíbles, de anécdotas entrañables y cada vez que se acercaba el final de la visita, me abrazaba fuerte y me decía: ¡No te olvides de mí, hijita! 


\section{Ella falleció.}

Los asuntos legales no permitieron que mi papá y sus hermanos vivan su duelo correctamente. La repartición de bienes enemistó a más de un hermano y la memoria de mi abuela era lo que menos primaba.

Llegaba el momento de reescribir mi cortometraje de tesis. Ese mismo día que replanteé la idea fue el miércoles antes de Semana Santa. Ese mismo día también tocaba desalojar el cuarto de mi abuelita. Dentro de la infinidad de cosas que había en su habitación, encontré una foto mía de cuando tenía dos años. Ella la había guardado y cuidado durante veinte años. No cabía duda, tenía que contar su historia. Tenía que darle vida a una de las tantas conversaciones que tuvimos y, como el cine lo puede todo, ahora sí sería posible de lograr.

\subsection{Misión y visión del cortometraje}

La intención principal de este proyecto es lograr una reflexión en los espectadores. Pretende cumplir un rol, no cuestionador, sino de enseñanza. Según datos del INEI, un 38,2\% de los adultos mayores de 70 años viven solos dentro de nuestro país. ¿No es acaso momento para pensar sobre esto? (INEI, 2018)

La misión, entonces, del personaje de Graciela es generar un entorno cercano, sensible y compasivo, apuntando a dos elementos importantes: la gratitud hacia nuestros padres y el tiempo que le dedicas a una persona. Asimismo, se quiere proyectar empatía e identificación, porque siempre se ha sido abuelo, padre, o nieto de alguien. Este cortometraje busca la unión, por lo que está dirigido a un público general, sin excepción.

Los que quedan se proyecta con un enfoque distinto. No solo el cine sirve para entretener, sino también para generar conciencia a través de un buen contenido audiovisual. Así pues, se busca reflexionar sobre la enorme responsabilidad que tiene un comunicador audiovisual en la creación de historias y se busca lograr cambios en la sociedad, así comiencen solo con una llamada a un ser querido olvidado. 


\subsection{Contexto y antecedentes audiovisuales}

El cine nació con la intención de dar a conocer situaciones humanas. Como explica Enrique Martínez-Salanova (2003) en su artículo El valor de cine para aprender y enseñar: "al cine le interesa «el drama humano», algo que le pasa a alguien" (p. 48).

Es así, que la ficción debe responder a la vida humana, ya que "el cine se adentra, inventa, reproduce o investiga sobre el ser humano y sus conflictos" (Martínez Salanova, 2003, p. 48)

Asimismo, "el cine contribuye al conocimiento de las personas, porque si hay un elemento diferenciador que determina la actitud ética de un cineasta ante el relato cinematográfico, éste es la mirada, el punto de vista que adopta y desde el cual cuenta la historia" (Martínez Salanova, 2003, p. 48).

Entonces, partimos de estas dos premisas. El cine como medio para la representación de situaciones y conflictos humanos; y, a la vez, como una forma de dar un punto de vista personal a través de la mirada ética del director.

Es por eso que la mejor manera para contar esta historia era un cortometraje cinematográfico.

Asimismo, en el camino, encontré otros cortometrajes y películas que me sirvieron de referencia para la creación de los personajes, la historia en sí misma y la puesta en escena.

Mi primer acercamiento a personajes de la tercera edad en el cine fue con la película francesa Amour (2013) dirigida por el alemán Michael Haneke. La historia de una pareja de músicos retirados, ya mayores, que se complica por el derrame cerebral que sufre Anne. Georges, su esposo, decide cuidarla y promete no dejar que ella regrese al hospital. Esta historia me sirvió como referencia para la creación de mi personaje principal. 
Si bien el personaje estaba inspirado en mi abuela, tenía que ser precisa con detalles como el vestuario, la atmósfera de soledad en un ambiente donde solo viven dos personas, las dinámicas de una persona mayor cuando vive sola $\mathrm{y}$, sobre todo, lograr esta sensación de ternura única del personaje de Anne. Amour fue clave para decisiones en arte, fotografía y narrativa.

Hálito de vida (2014) es un cortometraje dirigido por Jonatan Medina Espinal. Llegó a mi vida de casualidad; y sin querer, me hizo pensar sobre el significado de "hacer el amor". Esta es la historia de una pareja de ancianos que deciden un día volver "hacer el amor" como los viejos tiempos. Después de muchos contratiempos, ambos se quedan dormidos y no logran concretar nada. No obstante, al levantarse comienzan a bailar juntos. De esta manera, se dan cuenta que ya estaban "haciendo el amor".

Si bien, la historia que yo cuento no ahonda en temas amorosos, el aspecto que sí consideré es el baile. Y es que, según mi punto de vista, el baile es sinónimo de alegría, amor, amistad. Refuerza la ternura de un personaje y conmueve al espectador. Como una respuesta a mis dudas, comprendí que así tenía que cerrar mi primera escena con una escena de baile.

Casadentro (2012), dirigida por Joanna Lombardi, nos cuenta la historia de Pilar, una persona de 81 años que vive en una casa tranquila, donde el tiempo demora en pasar, así como los planos largos que acompañan el cortometraje. La calma de los espacios se perturba por la llegada de una de sus hijas. A partir de eso se inician los conflictos.

El personaje que llamó mi atención aquí fue Consuelo, la empleada que conoce absolutamente todo de su jefa, interpretado por Delfina Paredes. Consuelo se presenta como alguien más que una empleada del hogar, se presenta como una amiga dispuesta a satisfacer todas las necesidades de su jefa. Esta relación casi amical, me sirvió para plantear la relación entre Graciela y Chabela. Asimismo, ver la deslumbrante actuación de Delfina Paredes, hizo que pensara en ella en todo momento para interpretar a Graciela. 
Finalmente, Casadentro me ayudó a crear la concepción de los espacios. Toda mi historia ocurre en una casa, y esta casa cumple un rol importante dentro del cortometraje. Alfredo tiene clarísimo que se quiere quedar con ella. Entonces los espacios eran muy importantes. ¿Cómo hacer que, a pesar de tener cuatro personas hablando, la sala no pierda protagonismo? Allí estaba el reto. Sin lugar a dudas, Casadentro me sirvió de referencia visual. El cuarto de Graciela está muy inspirado en el cuarto de Pilar.

Para que el proyecto logre su objetivo, no solo fue suficiente recurrir a referencias audiovisuales, sino también investigar más la relación que existe entre la identificación, empatía y moral. El ser humano funciona de esta forma: se identifica con el otro porque siente lo mismo, porque recuerda lo que vivió o porque es humano como él. Se dice, así, que de la identificación a la empatía hay un solo paso. Entiéndase la empatía como "un sinónimo para la comprensión y asunción del estado emocional de otra persona" (Muzur, 2011, pág. 9). Una vez que hay empatía existe "la posibilidad de percepción del estado emocional ajeno, alentando el desarrollo de la cooperación, el altruismo y la no provocación del sufrimiento en los demás, sino la protección, la generosidad y la tolerancia ante la diferencia” (Muzur, 2011, pág. 11).

\subsection{Objetivos}

Siempre he creído en el poder transformador que tiene contar una historia, y uno de mis grandes objetivos dentro de esta carrera era eso, contar una historia que logre un cambio en el espectador. Entonces, vi en mi proyecto de especialidad la oportunidad de lograr este objetivo. La historia, por sí misma, busca dar una lección de vida, resumida en dos palabras: tiempo y gratitud. Este cortometraje busca demostrar todo lo aprendido durante los cinco años de carrera, en cuanto a la creación narrativa, desarrollo audiovisual y escritura de guion.

Asimismo, durante la producción, se ha buscado generar un buen ambiente de rodaje, de trabajo en equipo, y poner en prácticas mis habilidades de organización y liderazgo; respetando procesos, cumpliendo con fechas y dirigiendo a un todo un equipo humano para terminar la filmación sin contratiempos. 
Además, se busca realizar un producto audiovisual de calidad técnica a nivel profesional, junto a una propuesta estética limpia y creativa, que permitan que Los que quedan tenga potencial de ser proyectado en distintos festivales.

Finalmente, se busca dar vida a una experiencia muy común entre las personas mayores, que quizá suceda todo el tiempo y solo no es percibida del todo. De esta manera, se quiere generar conciencia, representación y, sobre todo, conmover a la audiencia; a través de personajes empáticos, con conflictos humanos y universales. 


\section{REALIZACIÓN}

\subsection{Plan de producción}

\subsubsection{Subfase previa (creativa)}

Antes de empezar a escribir un guion, se tiene que tener resueltas tres preguntas importantes: ¿Qué es lo que quiero contar? ¿Qué es lo que quiero lograr en el espectador? y ¿Para qué medio se producirá? Con esas tres cosas claras, puedes empezar a escribir una historia. En base a esto, se tiene en cuanta lo siguiente:

Más allá, de consideraciones artísticas o técnicas, el guion es el comienzo de todo: el sueño de un narrador que precede actores, directores de fotografía, jefes de producción, responsables de marketing, ingenieros de sonido y de efectos especiales, diseñadores de arte, montadores y, por supuesto, precede al director. (Sánchez-Escalonilla, 2016, p. 12).

Entonces, teníamos que tener varios puntos en consideración. La primera idea fue que mi historia tenía que tener un mensaje fuerte, que resuelva una problemática constante, es decir, que exista siempre; para que así el cortometraje no responda solo a temas efímeros, sino universales. ¿Qué más universal que la muerte, la vejez y el paso del tiempo? Este tipo de temas, responden comúnmente a un estilo: el estilo cinematográfico. Entonces, empecé a escribir un guion para una pantalla grande.

Tenía un nudo en la garganta con la reciente muerte de mi abuela y, encontrar mi foto en mi habitación me hizo reflexionar sobre la historia que quería contar. Iba a contar la historia de mi abuela, pero no sólo de ella, sino de muchas otras abuelas en el mundo. También contaba la historia de hijos, amigos, nietos. Es decir, una historia de todos.

Desde mi punto de vista como guionista, esta historia tendría como principal objetivo conmover a la audiencia. Como afirma Escalonilla (2016), "La verdadera 
tensión dramática se produce cuando el espectador se involucra en el argumento" (p. $31)$.

Entonces, a partir de eso se recurrió a imágenes que conmuevan: una amistad que traspase la muerte, pequeños guiños a la niñez, un baile entre dos amigas, una anciana vulnerable, unos hijos no agradecidos y un testamento escondido después de la muerte, diálogos reflexivos y sentimentales.

Fue con estas ideas previas que se empezó a escribir Los que quedan.

\subsection{Descripción del trabajo de preproducción}

\subsubsection{Elaboración del guion ${ }^{1}$}

La mayoría de ancianos pasan mucho tiempo en sus casas, ya sea porque no pueden salir, están enfermos o, simplemente, disfrutan la tranquilidad de sus cuartos. Entonces, comprendí que las locaciones tenían que ser interiores, que todo debía suceder dentro de una casa, y darle la importancia necesaria a esa locación. Sería, quizá el último lugar donde nuestra protagonista pasaría sus días.

Una vez planteado el espacio, nos volcaríamos en las acciones. Si nuestro tema es la soledad, nuestro primer encuentro con nuestra protagonista sería ella sola, mirando a su alrededor, esperando algo, quizá un cambio en su vida. De arranque la presentamos junto a su conflicto. Ella está sola y no le gusta esa situación, lo que nos da curiosidad si más adelante hará algo o no.

Entra un nuevo personaje a escena, viste de empleada, tiene un rostro amigable y sencillo. Entonces, la dinámica de ambas comienza. Vemos engreimientos de Graciela, lo que nos hace verla como una niña (muy típico que los ancianos se vuelvan como niños a una determinada edad), nos damos cuenta el rol que tiene Chabela en su vida: la protege, la cuida y, sobre todo, la quiere.

\footnotetext{
${ }^{1}$ Anexo 1
} 
En esa primera conversación conocemos su relación de amistad. Si bien la primera escena comienza triste, termina feliz, con un baile de dos amigas que se quieren, lo que genera ternura, nostalgia y empatía.

Después de una transición creativa pasamos a otro espacio de la casa: la sala. Aquí la casa muestra su presencia: los decorados, los muebles. Es una casa llena, pero vacía al mismo tiempo, está cuidada, limpia, ostenta lujo, dinero.

Presentamos a los hijos en el primer plano. Hasta el momento solo habíamos escuchado de ellos, ahora los vemos. Cada uno demuestra una personalidad distinta. No es necesario que hablen, por las acciones, ya los empezamos a conocer. Al crear los personajes de los hijos tenía algo muy claro: tienen que ser una muestra exacta de la sociedad. En un funeral, siempre hay uno sensible, siempre hay uno más serio y siempre hay uno convenido.

El juego de dos espacios durante la segunda escena nos permite crear una tensión dramática: algo va a pasar aquí. "Sin tensión dramáticas, las historias no resultan interesantes" (Sánchez-Escalonilla, 2016, pág. 28).

La escena en la cocina nos anticipa que esa caja es importante, pero ¿qué tiene? Y ¿dónde está Graciela si es que de verdad fingió su muerte? ¿Por qué Chabela está tan conmocionada? ¿Se murió de verdad o solo está nerviosa? Vemos a Chabela en conflicto interno. Algo tiene que decir.

La casa está presente en la conversación. ¿Ven que sí era importante? Y no solo está presente, genera conflicto entre los hermanos.

La entrada de Chabela, lo que cuenta y la reacción de los hijos al verla, refuerza la relación ya establecida en la primera escena con Graciela, también la personalidad de los hijos. Escalonilla menciona (2016):

La escaleta de nudos de acción de un guion es una de las fases vitales del proceso de escritura, pues proporciona la relación de episodios o golpes 
dramáticos que recorren el argumento, desde la secuencia de apertura hasta el suceso final (p. 41).

Sabía que la historia tenía que ir desencadenando misterios. Entonces, un golpe dramático de la historia sería la presencia de una caja y su contenido. Graciela sí había dejado un testamento.

La lectura de testamento representa esta liberación de nuestra protagonista. Dice todo lo que ha querido decir durante años. Asimismo, esa carta contiene una lección de vida: el tiempo dedicado a una persona no tiene precio. Se muestran personajes de la vida cotidiana, que ni siquiera tienen idea el bien que le hacen a una persona solo preguntándole “¿cómo están?” o regalando una sonrisa.

Se juega con el condicionamiento operante, desarrollado por B.F. Skinner, que es "una forma de aprender por medio de recompensas y castigos. Este tipo de condicionamiento sostiene que una determinada conducta y una consecuencia, ya sea un premio o castigo, tienen una conexión que nos lleva al aprendizaje" (Sincero, 2011, pág. párr. 1). Castiga la ingratitud, premia la atención brindada. Esto genera una enseñanza al espectador.

Asimismo, refuerza el lado lúdico de nuestra protagonista: una travesura de una niña. Recordamos, entonces, que los ancianos son como niños, al final de cuentas, y genera más empatía.

Finalmente, se quería que el guion no sea plano, ni siga una estructura narrativa clásica. Todo lo contrario, que sorprenda al espectador constantemente, con giros y decisiones inesperadas.

\subsubsection{Elección del casting}

Desde que busqué mis referencias visuales y me encontré con Casadentro, tenía claro que Delfina Paredes tenía que ser la actriz del corto. Cumplía con el perfil físico pensado para Graciela, además de tener un bagaje actoral increíble y de ser un ícono del cine peruano. Asimismo, su nombre le daría un peso al cortometraje. En un principio, 
Delfina se negó, ya que estaba superando un problema en la columna que no le permitía movilizarse. Sin embargo, a insistencia mía de que lea el guion, finalmente aceptó porque le gustó mucho la historia.

A partir de la elección del personaje principal, ya se podía conseguir a los hijos.

Se buscó, entonces, rasgos que coincidían con los de Delfina para hacer más verídico la conexión familiar. Además, los hermanos tenían que guardar cierto parecido entre ellos. Lo que también fue necesario era cumplir con las edades, ya que no podían ser tan jóvenes, ni muy mayores.

Me reuní con el director de teatro, Sergio Plaza, quién tiene contactos con actores del medio. Él asumió el puesto de asistente de dirección y jefe de casting durante la preproducción del cortometraje. Fue así que llegamos a Oscar Beltrán, Natalia Cárdenas y Caroll Chiara. Los tres se sintieron conmovidos por la historia y aceptaron rápidamente.

Con la que más tuve problema fue con Chabelita. Cuando escribía el guion, pensé todo el tiempo en Silvia Majo para el papel. Sin embargo, Silvia ya tenía compromisos en las fechas de grabación. Lo que hice fue ver programas de televisión nacional y fue así como llegué a Úrsula Mármol, me contacté con ella, le pedí su reel, hizo un pequeño casting virtual y quedó.

Por temas de presupuesto (costear cinco actores profesionales), los personajes como el panadero, la vecina y la enferma serían familiares y amigos; y el abogado que tenía una participación pequeña, sería el papá de una amiga, que en la vida cotidiana es un verdadero notario.

\subsubsection{Elección del equipo técnico}

Yo era consciente que no tenía el presupuesto para contratar un equipo técnico profesional. Pero también era consciente que la falta de presupuesto no era impedimento para contar con uno talentoso. Recurrí, entonces, a amigos muy cercanos con mucho talento y amor por el arte. 
Ya tenía asistente de dirección: Sergio Plaza, que desde un principio me ayudó con el tema de actores y me apoyó emocionalmente durante la preproducción.

Ahora me faltaban los demás.

Hace algunos años, junto a un grupo de amigos fuimos parte de una productora llamada Inside Project. Aquí, conocí el trabajo de mis amigos más cercanos y me di cuenta el talento que tenían, además del profundo cariño hacia a ellos. Es por eso que puse mi entera confianza para la dirección de fotografía a Alejandro Serruto. Él ya ha tenido experiencia grabando cortometrajes, ha hecho documentales junto a Juan Andrés Coriat y ha ganado premios. Su nivel de compromiso con la historia fue desde el principio. La única condición que puso fue que él sea quien elija a su asistente. Llamó a Frabrizio Rivva, a quien conocí el mismo día de rodaje. El equipo de fotografía ya estaba completo.

Dirección de sonido lo haría uno de los mejores sonidistas que tiene la Universidad de Lima: David Saurre. Además de ser mi colega en el SERCOM, también he trabajado con él en rodajes. El más cercano fue Historias de un mundial de Creativita. En ese mismo rodaje conocimos a Lia Santamaría, a quien llamé para que, al igual que en el rodaje anterior, también sea asistente de sonido.

El tiempo pasaba y aún no conseguía productora.

El primer conflicto que ocurrió fue cuando David me dijo que no podría estar el primer día de rodaje. Entonces, tenía que buscar a alguien que haga sonido directo para el día uno. Casi todos los sonidistas estaban ocupados o participando en el concurso 48 Hour Film Project edición Lima. Hice muchas llamadas hasta que Ana-Lucía Moreno me contestó y con mucho cariño decidió ayudarme.

Foto y sonido listo.

Abril Ibérico había comenzado a trabajar conmigo en la Universidad de Lima, en el Servicio de Fotografía y Computo hace unas semanas. Yo conocía su trabajo en 
arte de varios cortometrajes que me había mostrado y, hace unos meses había trabajado en una producción con una actriz de la tercera edad. Entonces, tenía el arte clarísimo. Cuando se lo propuse, se emocionó tanto que al día siguiente ya tenía toda una carpeta de arte armada. Abril me demostró mucho profesionalismo y un talento increíble. La asistente de arte fue Alexia Gildemeister. Además de tener una gran química con Abril, en Historias de un mundial Alexia y yo habíamos sido asistentes de arte, por lo que confiaba plenamente en su trabajo.

Antes de tener alguna idea de guion, inclusive mucho antes de tener alguna idea en general para mi tesis, Diego Chavez se sorprendió tanto por mis trabajos en Fotografía e Iluminación, que se ofreció a ayudarme en cualquier otro próximo proyecto que tenga. Me acordé de este ofrecimiento y empecé a ver sus últimos trabajos. Trabajo para Facusnatch en el área de foto y me sorprendió su trabajo. Entonces, lo llamé para que sea gaffer. Él se emocionó, leyó la historia y estuvo encantado de ayudarme. Él llevó a Nicole Sanchez como luminito principal. A ella recién la pude conocer durante el rodaje, y fue una asistencia increíble para la iluminación y el armado de equipos.

Cuando me di cuenta que no podía seguir produciendo y dirigiendo al mismo tiempo, me junté con mi mejor amiga Alessandra Vera. Nos habíamos conocido grabando un documental en el norte del Perú y desde allí descubrimos que ambas teníamos una gran pasión por lo audiovisual. Alessandra ya había producido cortometrajes antes, y había ganado el concurso 48 Hour Film Project edición Lima. Leyó el guion y no dudo en ningún momento de ayudarme y sacar adelante este proyecto. Ella decidió llamar a Alejandra Ontaneda para que su apoyo en la grabación. A ella también la conocí el primer día de rodaje. (Después me enteré que era economista, por eso Alessandra le dio el cargo de encargarse del presupuesto y pagos)

Maquillaje estuvo a cargo de Macarena Bancayán, el primer día; y por Brenda Cruzado, el segundo. Aunque la propuesta de maquillaje no era tan exigente, sino más natural, se hizo, igual, una prueba de maquillaje con ambas.

Además de todo este grupo humano increíble, se unieron al team Esperanza Loayza, como productora ejecutiva y jefa de catering; Camila Gómez, como asistente 
de catering y organización de movilidades; y Patricia Garrido, como asistente de catering y encargada del transporte privado de actores y equipos.

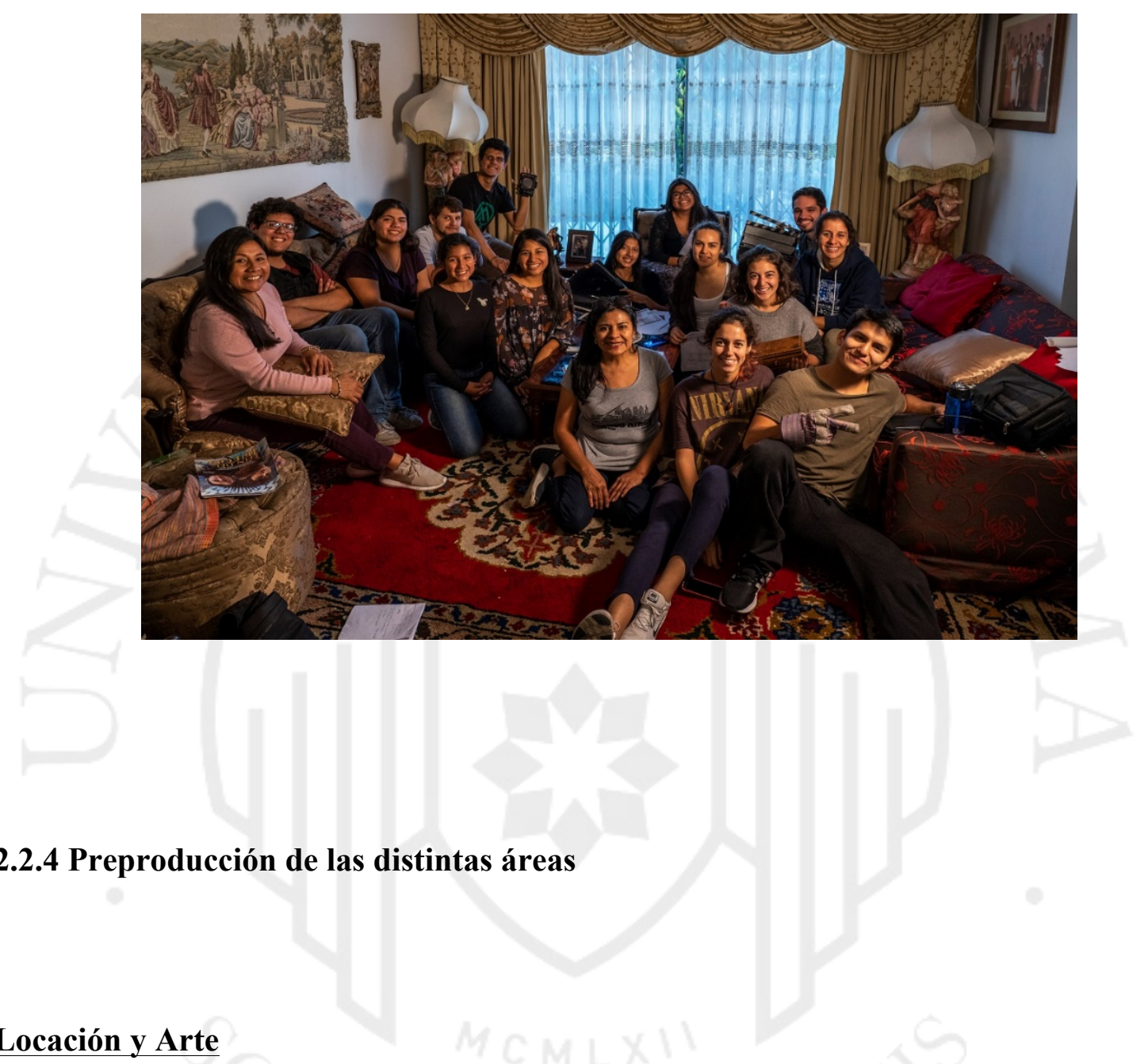

Después de terminar el guion y tener el visto bueno del catedrático Giancarlo Cappello. Hice una carpeta de producción, con desglose de casting y referencias de locaciones y arte. Esta carpeta se la pasé a Abril y ella la afinó mucho más. Me reuní con ella y coincidimos en que conseguir la locación era el siguiente paso inmediato. Como afirma Michel Chion (1990) en su libro El cine y sus oficios :

Dado que el cine, como sabemos, es el arte de expresar lo interior mediante lo exterior, una de las funciones principales del decorado de cine es traducir el mundo interior de un personaje, o al menos, manifestarlo en una serie de detalles expresivos y personales (p. 155). 
Teniendo ya establecido los días de rodaje, decidí llamar a amigas que vivían en casas de sus abuelas o en casas antiguas. Macarena Bancayán respondió a mi llamado y me dijo que encantadísima, que estaría feliz de ser parte de un momento tan importante para mí. Posteriormente, se visitó la casa junto con la directora de arte. La locación se prestaba para todo, cumplía con exactitud con todas nuestras referenciales visuales. Se trabajó un concepto de arte barroco y ostentoso.

Los escenarios del cine, entonces, se ubican en primer plano; necesitan ser no sólo un contenedor para los sucesos humanos, sino entrar dinámicamente en la acción narrativa. (Bordwell \& Thompson, 2003, pág. 159).

Es por ello que, la casa tenía que estar llena de cosas, muy adornada y los espacios tenían que ser grandes; para que dé la sensación de que Graciela se siente abrumada y sofocada por la soledad y los espacios. Siguiendo el postulado de Bordwell y Thompson: "El diseño general de un escenario puede determinar significativamente cómo interpretamos la acción de la historia” (Bordwell \& Thompson, 2003, pág. 160) .

Ricardo Bedoya e Isaac León (2003) sostienen en su libro Ojos bien abiertos lo siguiente: "La práctica de color en el cine se ejercita a partir de la aplicación de pautas expresivas" (p. 116). Por lo tanto, se acordó que la paleta de colores sería desaturada y en una gama de marrones y rosados; para acentuar, un tanto, el desgaste del paso del tiempo, la vejez y la soledad. "También se restó saturación (...) con el fin de mostrar los efectos de un mundo opaco y depresivo" (Bedoya \& Frías, 2003, pág. 121).

De igual forma, según Ricardo Bedoya e Isaac León (2003) "Los vestidos son signos primordiales de la apariencia" (p. 152). Por esta razón, buscamos que Graciela vista de forma sencilla, no de manera ostentosa. A diferencia de sus hijos, que sí tenía que estar en un código de vestimenta más elegante.

Es entonces que Abril se puso en contacto con el equipo de producción para que se contacten con los actores principales. Ellos traerían su propio vestuario, de acuerdo a las referencias, lo que nos permitiría reducir los costos. El uniforme de la empleada y el vestuario de los extras nos fueron prestados por amistades cercanas. Todos los elementos de utilería se consiguieron de manera gratuita. En el arte no se gastó mucho, solamente en su transporte. 


\section{Fotografía}

El director de fotografía es un pintor, pero un pintor singular: solo puede elegir parcialmente sus instrumentos y sus colores, y procede por sustracción, como si partiese de un cuadro lleno de detalles para suprimir las tres cuartas partes. A pesar de estas extrañas condiciones de trabajo, a veces consigue hacer maravillas. (Chion, 1990, pág. 211).

Así que llegaba el momento de componer el guion en imágenes.

La locación nos permitía trabajar en la propuesta de fotografía. Me reuní con Alejandro Serruto y fuimos nuevamente a la locación. Acordamos que grabaríamos con una Sony As7III, en formato 4K. Se usarían lentes angulares $(24 \mathrm{~mm}, 35 \mathrm{~mm}$ y $50 \mathrm{~mm})$ para aumentar las distancias visuales y dar sensación de un espacio solo. Sin embargo, en los momentos de más tensión sentimental, se utilizaría un lente de más distancia focal $(85 \mathrm{~mm})$, para hacer más cercana la situación.

Acordamos, también, que se trabajaría con aperturas de lente entre f/1.4 y f/4, para tener poca profundidad de campo. Esto le daría a la imagen un aspecto más cinematográfico y nos permitiría jugar con el desenfoque, como se percibe, sobre todo, en la escena del comedor.

En esta segunda visita a la locación, observamos las fuentes de luz para realizar de esta manera una planta de luces. Decidimos, entonces, la lista de equipos necesarios. Como no había presupuesto para alquilar equipos, recurrimos a equipos propios y pedimos prestados equipos de iluminación y sonido a la Universidad de Lima.

Después de visitar la casa, nos reunimos nuevamente para realizar el guion técnico ${ }^{2}$.

Para nuestra propuesta de plano utilizamos las siguientes referencias visuales.

\footnotetext{
${ }^{2}$ Anexo 3
} 


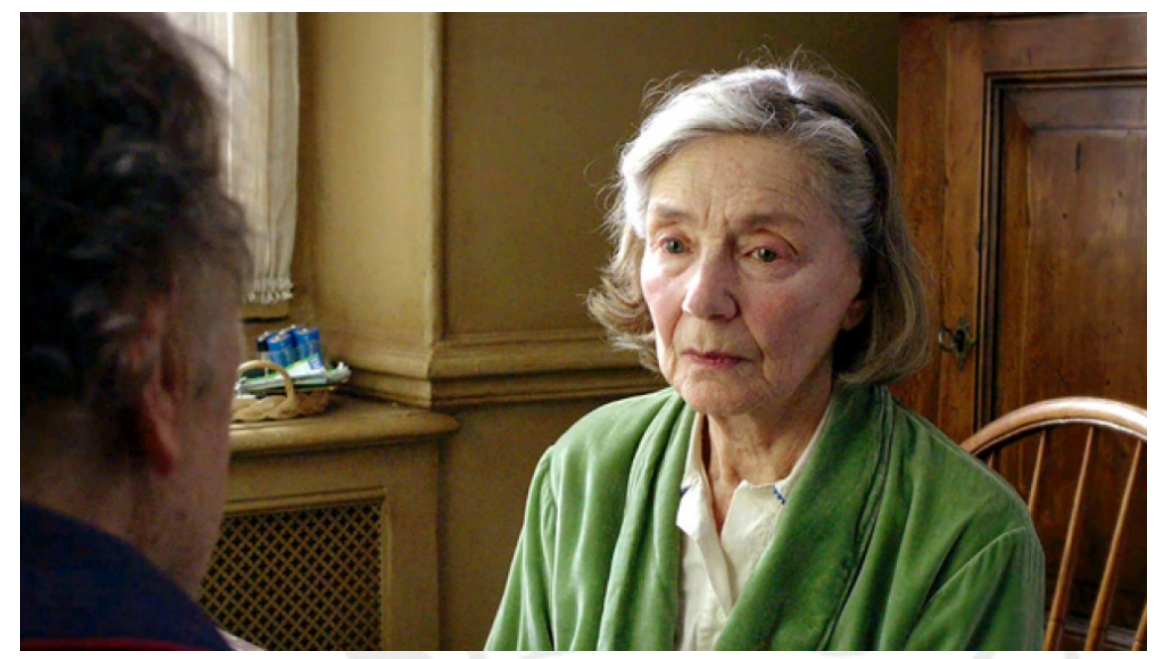

Fotograma película Amour (Heneke, 2013)

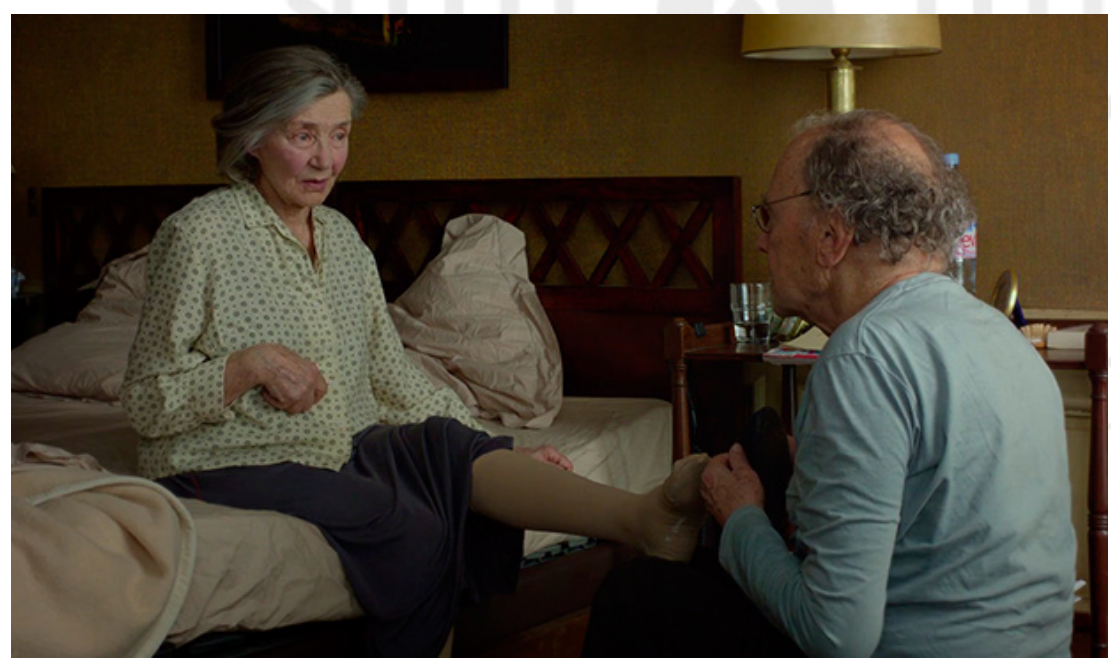

Fotograma película Amour (Heneke, 2013) 


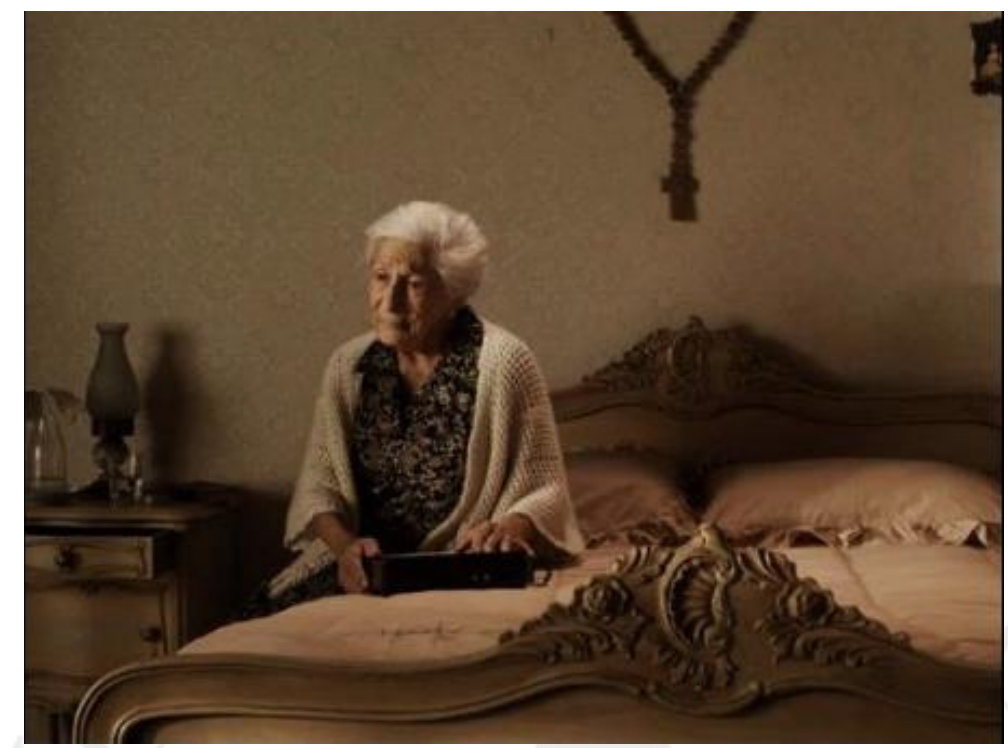

Fotograma película Casadentro (Lombardi, 2012)

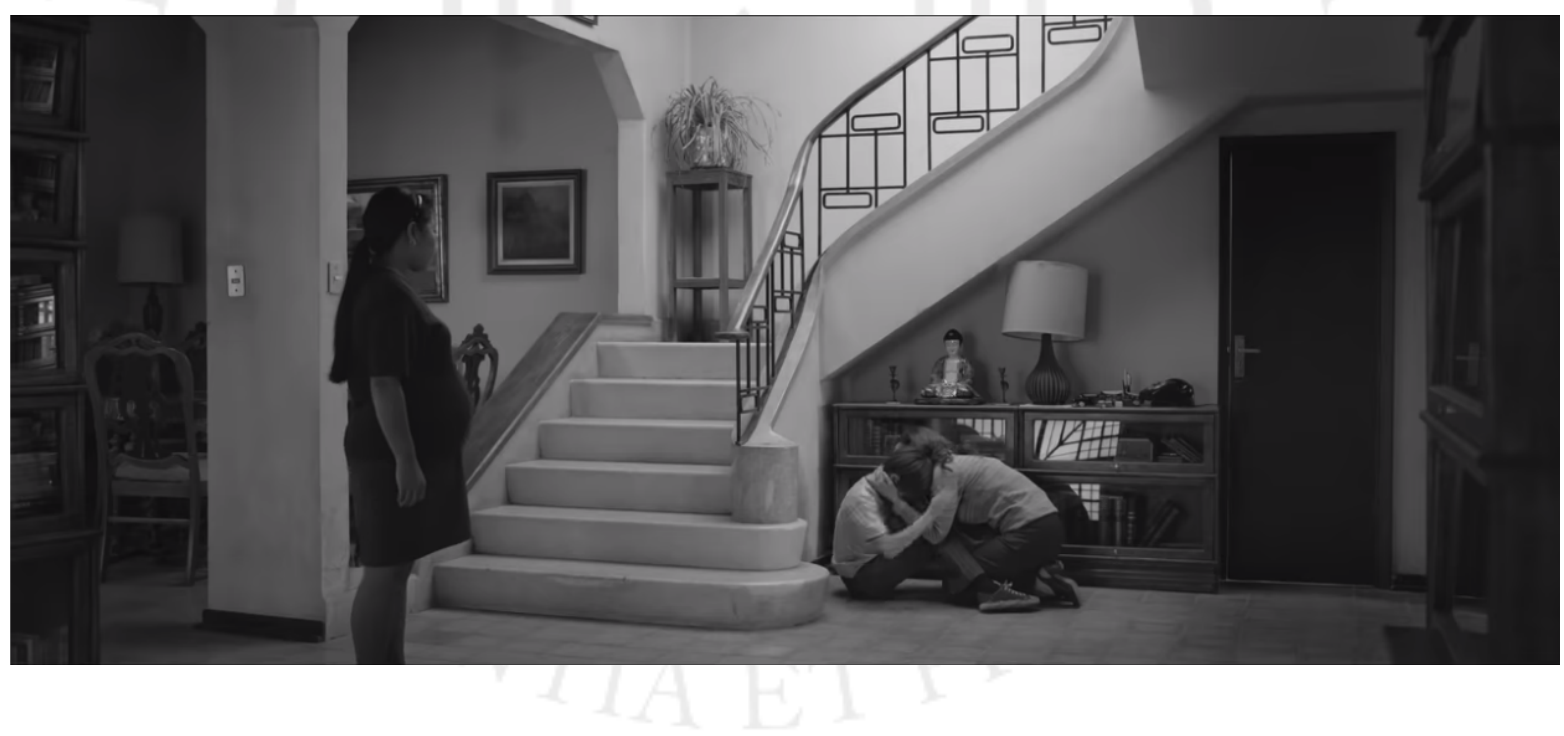

Fotograma película Roma (Cuarón, 2018)

Sabía que era necesario arrancar con planos detalles, que contextualicen la situación actual de nuestra protagonista; mostramos pastillas, cartas, imágenes religiosas. Para irnos adentrando un poco más a su mundo. 
Asimismo, era necesario crear una atmósfera donde el tiempo demore en pasar. Cuando uno es ya mayor, y más aún, si estás echada en una cama la gran parte del día, el tiempo se hace largo. Entonces, los planos siguientes serían así, nos mostrarían a ella en su soledad, buscando a ese amante que se fue y viendo recuerdos felices de algún momento de su vida. Este recuerdo sería interrumpido por la llegada de Chabela con el almuerzo.

La conversación sería cubierta con un plano, contra plano y uno conjunto a contraluz. Sin embargo, en el plano de Chabela nos pasó lo siguiente. Teníamos que decidir si perder el plano, ya que ella estaría completamente a contraluz o romper el eje. Preferimos romper el eje. Junto con Alejandro Serruto, director de fotografía, evaluamos lo siguiente: son dos personas conversando, únicamente esas dos personas se encontrarían en el espacio, entonces no sería tan notorio el cambio de eje. Como señala Chion:

Casi todos los directores de fotografía reivindican ahora la lógica visual, aunque sea en términos menos radicales: muchos aceptan la necesidad de hacer trampas, muchas veces con fines estéticos por lo que se refiere a los rostros, pero también con fines barrocos o expresivos. (Chion, 1990, pág. 215).

La escena termina con una transición elíptica. "Una analogía de contenido material, es decir, identidad, homología o semejanza como base de la transición" (Martin, 1995, p. 96). En este caso nuestro objeto es la foto. Asimismo, este paso del tiempo, responde a una elipsis dramática y simbólica. Dramática porque aporta al drama de la historia. Es un lapso de tiempo que el espectador no conoce. No sabe que ha sucedido después de esa conversación. ¿Graciela habrá muerto? ¿Graciela habrá fingido su muerte? “(...) hay que dejar que el espectador ignore ciertos elementos que condicionen el interés que tomará después de la acción” (Martin, 1995, p. 86).

Por otro lado, es simbólica porque "abarca un significado más amplio y profundo" (Martin, 1995, p. 88). De un momento feliz, pasamos a uno triste, así de rápido. Un día celebramos la amistad, la vida de una persona, y al siguiente la estamos recordando desde una foto que será puesta al centro de la mesa. Así de rápido se desvanecen los momentos felices, el tiempo es tan relativo como la felicidad. Esta 
transición buscaba eso. Dos momentos completamente distintos unidos por una sola persona.

La transición se transformaría en un plano secuencia que nos permitiría conocer la actitud de cada uno de los hijos. En este segundo espacio, serían necesario planos abiertos, generales; para demostrar la opulencia de la casa.

Durante la conversación con el abogado, quería hacer la diferencia de los dos hermanos, más duros y quizá más "materialistas", con Amelia, más sensible y más dolida.

\section{Sonido}

Ser cada vez más ligera y discreta, como una oreja volante, sin restricciones ni límites, es el ideal de la toma de sonidos. (Chion, 1990, pág. 231).

En cuanto a sonido, David evaluó la locación, también. Acordamos que se quería un registro de audio completo para tener más posibilidades durante la mezcla de audio. Se hizo una lista de sonidos $^{3}$ necesarios para ser captados y acordamos grabar otros como foleys. Se utilizó un boom y dos pecheros.

\section{Plan de rodaje y ensayo con actrices}

Mientras esto se hacía, ya los actores estaban confirmados. Con ambas cosas ya hechas (guion técnico y casting cerrado), podíamos armar el plan de rodaje ${ }^{4}$. Me reuní con Alessandra Vera y quedamos en que, por temas de practicidad y presupuesto, el primer día grabaríamos todos los planos con Delfina Paredes. El segundo día serían todos los planos con los hijos, el abogado y Úrsula Mármol. También coordinamos las horas de llamado ${ }^{5}$, para que no haya algo que salga mal.

\footnotetext{
${ }^{3}$ Anexo 2

${ }^{4}$ Anexo 5

${ }^{5}$ Anexo 6
} 
Por último, ya teniendo todo listo, agendé un día de ensayo con Delfina y Úrsula, las actrices principales. Aquí me tomé el tiempo de explicar el perfil de personaje de cada uno. Graciela, por un lado, era tierna, engreída y dulce. Por otro lado, Chabelita, era muy humilde, servicial y protectora. Se hizo lectura de guion y se resolvió las dudas sobre la historia. Les dije algunas indicaciones precisas y ensayamos.

Cabe resaltar que, si bien solo tuvimos un mes para la preproducción, agradezco el nivel de compromiso y amor de todo mi equipo humano. Se logró una buena organización y un buen trabajo.

\subsection{Descripción del trabajo de grabación}

\subsubsection{Día 1}

A los problemas típicos de un rodaje (como salirse del presupuesto, no cumplir el plan de trabajo, peleas con otros participantes, inclemencias, problemas de producción) se añaden las angustias personales del director, que se siente un hombre acosado, centro de mil decisiones que hay que tomar y responsable de una enorme empresa. (Chion, 1990, pág. 70).

Dejando de lados los nervios y las ansiedades, me propuse a que este día iba a ser bueno. Tenía dos cosas claras: mi nivel compromiso con la historia y el respeto hacia todas las personas que hacían posible que este cortometraje se estuviera grabando.

Por temas de tiempo no se tuvo una reunión general con el grupo completo. No todos se conocían entre sí y se corría el riesgo que no haya armonía en el grupo. Yo tampoco conocía a todos los asistentes de área, solo a los directores. Sin embargo, grande fue mi sorpresa cuando todo el equipo se compenetró muy bien, crearon rápidamente amistad y trabajaban muy bien juntos.

Cuando llegué a la locación, ya estaban todos los equipos allí, habían llegado antes de la hora prevista. Este tipo de compromiso por parte de mi team, me dio la 
confianza absoluta en ellos. Los reuní a todos, me presenté para los que no me conocía y nos pusimos a trabajar.

A mí, personalmente, me gusta comprometerme con cada una de las áreas al momento de dirigir. No hay decisión que se tome, sin mi previa aprobación. Aquí me di cuenta cuánto me había valido, haber hecho de todo durante mis cinco años de carrera, porque como es sabido, no siempre se dirige. Algunas veces, te toca cargar el boom, hacer arte, ser asistente de producción, ser continuidad. Pero todo eso servía para en ese momento poder liderar cada uno de los cargos y tener empatía con el otro, porque conocía el trabajo de cada uno de ellos.

En cuanto a la dirección de actores, tenía un gran reto. El primer día, debía hacer todas las tomas con Delfina Paredes. Y fue un gran reto porque nunca había dirigido a alguien de 84 años y con tal bagaje actoral. Debo admitir que tuve que tener mucha paciencia, ya que Delfina todo lo hacía con mucha calma y sin prisa. Pero fue increíble dirigirla. Ella constantemente aportaba a la historia y a las acciones de su personaje. En verdad, aprendí mucho de todo su conocimiento, y su vitalidad me inspiró.

La química entre Úrsula y Delfina fue casi inmediata. Úrsula después me confesó que ella era muy fanática de Delfina y cuando yo le dije que ella sería la actriz, no pudo estar más feliz. Ambas fueron increíbles. Las tomas salían rápidamente porque a la primera captaron todas mis indicaciones.

Como directora, incentive al equipo a adelantarse al plan de rodaje. Si es que una escena estaba siendo grabada y alguien del team estaba libre, le pedía que vaya preparando la otra escena. De esta manera, se ganaba tiempo.

Ahora nos tocaba hacer todas las tomas de apoyo con los diferentes extras. Arte tuvo un trabajo importante. Supimos manejar muy bien los cambios de vestuarios de Graciela y también los vestuarios de cada uno de los extras.

El primer día de rodaje terminó sin contratiempo. Producción se encargó de organizar los traslados de los actores. Una vez que ellos se fueron, reuní a mi equipo 
para felicitarlos por el excelente trabajo que habíamos hecho. Les volví a agradecer por la muestra de amistad tan grande que estaban teniendo conmigo. Después, me reuní con las cabezas de área para explicar cuál sería el plan del día siguiente. Aceptando las propuestas de cada uno, nos fuimos a descansar para al día siguiente empezar de la mejor manera.

\subsubsection{Día 2}

Si en el primer día el reto era Delfina, este segundo día fue la Maratón Life Lima 42k y el hecho de que tenía a Oscar Beltrán solo hasta las 3 de la tarde. La maratón nos hizo retrasar una hora y media. Mi productora entraba en crisis, yo la calmaba diciéndole que todo iba a salir bien, que confíe en su directora. Los tres hermanos congeniaron de inmediato. Los reuní a los tres para resolver dudas sobre sus personajes y darles las indicaciones necesarias. Con el abogado, recurrí a la técnica de modular los elementos de la voz. Él no es actor, entonces, tenía algunas entonaciones no correctas para el corto. Lo que hice fue sentarme con él y darle indicaciones tan precisas como ponle énfasis en tal palabra, baja el volumen aquí, alarga más esta sílaba, etc.

Eran las 2:00 pm y aún me faltaba grabar cinco planos con Óscar. Y Alessandra no paraba de alarmarme por la hora. Yo en el fondo guardaba la calma y le decía que confíe, lo íbamos a lograr. A las 2:45 pm estaba mandando a grabar el último plano de Óscar. Como lo tenía hasta las 3:00 pm, aproveché de hacer más planos con él.

El plan de rodaje para ese día estaba destinado hasta las 6:00 pm. A las 4:45 estábamos guardando equipos.

Fue un gran día de rodaje. Todo salió como estuvo planeado. Al final del día, di mis palabras de agradecimiento hacia mi equipo y me sorprendió cuando todos me agradecieron por darles la oportunidad de trabajar conmigo.

Mientras todos se iban, yo me quedé revisando los clips haciendo muchas copias de estos, solo por precaución. 


\subsection{Descripción del trabajo de postproducción}

\subsubsection{Edición de imagen}

La tradición considera complementarias las tareas del director de fotografía y del montador: el primero se ocupa de la atmósfera visual y el segundo del ritmo, aunque este último trabaja con un material impuesto en el que, salvo excepciones, no puede cambiar nada. (Chion, 1990, pág. 333).

Al día de terminar de grabar, ya había un corte grueso. Se comenzó a sincronizar los audios con la imagen, apoyándonos del script. Este primer corte cumpliría solo con lo esencial: contar la historia. Me di cuenta que no era tan conveniente que la directora edite su propio corto. Por lo que, para el corte fino, acudí a Anishell Freundt. Ella, desde un punto de visto totalmente externo, ayudó a que el cortometraje tenga mucho más ritmo, añadió planos detalles que ayudaban a contextualizar la historia y reacciones que ayudaban a darle más emoción a las situaciones. A través del cambio de espacios, Anishell pudo crear un clímax en la segunda escena. Además, le dio más ritmo a la lectura de testamento para que el corte de la imagen vaya al ritmo de la voz de Delfina. A la semana, me entregó una versión. Le mandé algunas correcciones. La semana siguiente a esa, ya estaba lista la versión más convincente, la cual se mandaría a colorizar y sonorizar.

\subsubsection{Colorización}

En cuanto a colorización, acordé con Alejandro Serruto que mantenga la desaturación y que las sombras sean muy tenues. Se acordó también mantener los colores marrones y rosados. Se corrigió algunas tomas a contraluz y se colocaron las barras negras para darle un tono más cinematográfico a la imagen. Durante la lectura del testamento le pedí que subiera ligeramente la saturación en los momentos que Graciela recuerda como más felices, para hacer una pequeña distinción. 
Para colorizar se usaron los programas Lumetri y Colorista, ambos de Premiere del paquete Adobe. Lumetri es el programa por defecto que brinda Premiere, este se usó específicamente para hacer la corrección de color de las tomas. Luego, se usó Colorista que es un Plug/in de Premiere para resaltar los colores fríos y generar contrastes.

\subsubsection{Diseño sonoro y musicalización}

La postproducción de sonido fue elaborada por Isa Abad, director de diseño sonoro en Fade Out. Él trabajó particularmente en los ambientes. La zona donde grabamos fue cerca a la Javier Prado, por lo que en todo momento pasaban carros. Entonces, se tuvo que recrear un nuevo ambiente, mucho más sosegado: sonido de pajaritos, una atmósfera más tranquila. Se recurrió a Foleys para sonidos específicos como la servilleta, cuchara, caja al colocarse, etc.

Durante la grabación, la canción escogida para el momento del baile fue a pedido de la actriz: Marionetas de Cartón de Los Iracundos. Sin embargo, desde un principio, yo ya tenía contemplado componer una canción exclusivamente para esta escena; ya que el cortometraje tenía que ser enteramente original.

Lo que hicimos fue poner esa canción de referencia para que ella se moviera a ese ritmo. Entonces, al momento de componer, se tuvo que lograr una melodía que siguiera el ritmo del baile, asimismo, la letra debería responder a la métrica de la canción original. Luego, me reuní con el musicalizador Diego Vela, egresado de la Escuela de Música de la Universidad Católica con un Máster en Musicalización para Cine. Le expliqué exactamente lo que buscaba para esta parte del cortometraje.

Cuando un escritor trabaja para el cine, se le llama guionista; cuando un pintor se ocupa de la dirección artística de una película o realiza sus decorados, se le llama director artístico o decorados; pero un compositor que trabaja para la pantalla grande se sigue llamando compositor, y lo que produce sigue siendo música. (Chion, 1990, pág. 387).

La letra fue escrita por Alessandra Vera. Me reuní con ella y le conté exactamente lo que buscaba, le pedí que tomara el siguiente frame de referencia. 


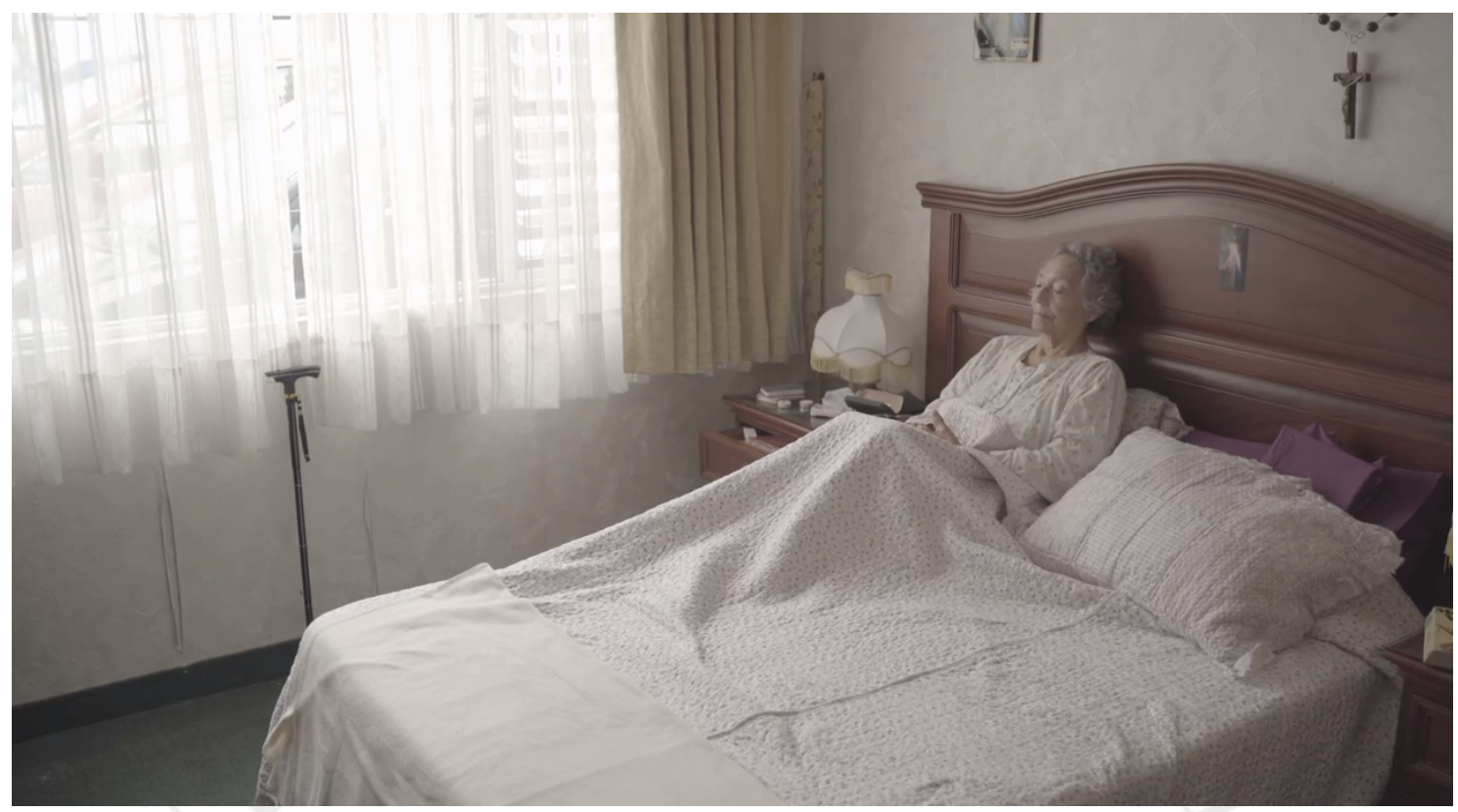

Y el resultado fue el siguiente:

\section{SANTA CARMEN}

¡Cuántos atardeceres en mi ventana! En la casa de todos los recuerdos Que se irán conmigo cuando me vaya Viví el amor de formas tan ordinarias

Tan hermosas que no pueden explicarse

Solo pueden sentirse cuando caen Los rayos de luz del sol antes de irse Si sigues aquí, busca el verano eterno

No olvides del sol Que vio todo nuestro amor

No olvides el sol

Sobre las sonrisas

Y sobre tu piel

Que seguirá saliendo (bis)

Aunque yo me vaya 
La segunda parte que correspondía musicalizar era la lectura de testamento. Diego propuso colocar un sonido de suspenso desde el momento que entregan la llave, a mí me pareció buena idea y lo pusimos. Al momento de componer esta parte de la música, le pedí a Diego que usará como base instrumentos de cuerdas, ya que el piano me parecía muy melancólico, triste y hasta dramático. También separe la lectura de testamento por momentos.

- Primer momento: Graciela dirigiendo a sus hijos y hacienda mea culpa.

- Segundo momento: Repartición de bienes a las personas que más tiempo han pasado con ella. Aquí la música se transforma en esperanza, en ilusión. Graciela está premiando la amabilidad de la gente, personas que con pequeños gestos logran un bien a la sociedad.

- Tercer momento: Cuando le entrega la casa a Chabela. A ella ya la conocemos, entonces este momento debe ser muy emotivo para crear mucha más empatía con el público. Por ello, la música tiene que aportar para lograr que el espectador que se conmueva.

- Cuarto momento: Lección final. Aquí la melodía de lo que estaba arriba con el recuerdo de Chabela baja, porque Graciela dará sus últimas palabras. Se crea una sensación de suspenso que se alargará hasta la escena final del cortometraje.

Si bien la base es de cuerdas, con Diego acordamos que para cada uno de estos momentos iríamos agregando un instrumento en particular. El que más resalta es la presencia del corno francés durante el tercer momento. 


\section{LOGROS Y RESULTADOS}

El cortometraje se estrenó el 7 de diciembre del 2019 en la Ventana Indiscreta en la Universidad de Lima. Para esto, se exportó una versión con las siguientes especificaciones, que corresponde a un formato de cine: 1920 x 1080, con códec H264 y con la extensión mp4. Este primer estreno, fue especialmente dedicado al equipo técnico, actores y familiares.

Hasta el momento, el corto ha recibido muy buenos comentarios. No hubo espectador en esa sala que no se haya sentido conmovido con la historia.

La narrativa lúdica y no convencional hace que el espectador esté enganchando en todo momento. Asimismo, el perfil de cada uno de los personajes logra crear una gran empatía.

La dirección de actores en base a la verdad, es decir no llevada al extremo, ni a la exageración, sino de forma exacta, hace que ningún personaje parezca una caricatura. Delfina Paredes, por su parte, es excepcional. Llena el cuadro con su mirada, su voz, sus acciones.

La dirección de arte crea una atmósfera de espacios llenos que en realidad están vacíos, solos. La paleta de colores desaturada va muy bien con la personalidad de Graciela. La escena inicial es perfecta para enamorarse de la protagonista y marca el tono del cortometraje, ya que comienza triste y termina de manera positiva, con esperanza.

La lectura del testamento les pareció una excelente idea, porque logró cambiar el rumbo de un drama convencional. Sorprende. Atrae. Enseña.

Aquí me gustaría contar una anécdota. Después de mostrar el cortometraje, una de las personas de la sala se acercó a mí y me dijo que lo primero que haría al salir sería llamar a su abuelita, y mañana mismo la visitaría. Eso me sobrecogió como directora, ya que veía que la historia estaba logrando su objetivo. 
Algunos comentarios fueron: "Recordé a mis abuelos con cariño, por muchas de las cosas que la Sra. Graciela hacía en la cama", "La historia es muy conmovedora y me logró atrapar el tierno y crudo comienzo", "Me gustó bastante: hay dulzura, comedia y tensión", "El guion me parece perfecto y te atrapa la forma en que la señora viejita habla", "Me encantó el final, me parece muy emotivo que enfocarán a la señora que la cuidaban".

Además, Los que quedan formó parte de la selección oficial del Festival Hecho Por Mujeres y es parte actualmente de la preselección del Festival Biarritz América Latina.

Después de estos festivales se planea mandar el cortometraje a otros festivales ya sean nacionales como internacionales. Por lo que, se ve necesario subtitular el corto al inglés.

Asimismo, se logró una satisfacción personal al ver que algo que nació como una idea cobró vida y logró hacer reflexionar al aún poco público que ha visto el cortometraje. 


\section{LECCIONES APRENDIDAS}

\subsection{Planeamiento y rodaje}

En un inicio para mí fue un reto producir un cortometraje en exactamente un mes y con el presupuesto justo: contratar cinco actores profesionales, costear almuerzos, catering, movilidades, alquiler de equipos, contratar personal humano. Sin embargo, recibí el apoyo de muchos lados y de distintas personas. Muchas de las cosas conseguidas fueron gratuitas.

Algo que aprendí fue que para la próxima producción que realice, sería conveniente pedir ayuda financiera, ya sea a través de crowdfunding o presentar el guion a un concurso de realización.

Ya en edición me di cuenta las consecuencias fatales de no contar con un monitor externo, exclusivamente para el director, ya que muchas tomas se cortaron antes de lo que yo hubiera querido. Eso me quito algunas reacciones necesarias que hubieran enriquecido mucho más el cortometraje.

Si bien dentro de mi rodaje todo mi equipo se llevó muy bien, corría el riesgo que no congeniarán a la primera, por lo que, para mayor seguridad, yo sí vería necesario en una próxima vez tener reuniones previas al rodaje.

Asimismo, pudimos ahorrar mucho más tiempo si es que teníamos la locación exclusivamente para nosotros. Si bien no fue un inconveniente, teníamos que esperar a que las personas de la casa se desocuparan del todo para recién grabar.

Por último, me hubiera gustado tener una lectura de guion previa, no solo con Delfina y Úrsula, sino con todos los actores. Así, la segunda escena hubiera salido mucho más rápida. 


\subsection{Conclusiones}

Los que quedan me brindó una gran enseñanza tanto en el lado profesional, como en el personal. Una de mis metas antes de terminar la universidad era dirigir un cortometraje, y que la creación sea exclusivamente mía. Y no buscaba solo contar una historia, sino que esta historia logre un cambio en las personas y sea la voz de aquellas que quizá no pudieron expresarse en algún momento.

Por otro lado, descubrí en mí capacidades de liderazgo y de trabajo en equipo. Logré reunir a un grupo de personas maravillosas y de mucho talento que me ayudaron con total desprendimiento. Logré dirigir a mi equipo y a mis actores de tal forma que pude sacar lo mejor de ellos. Se trabajó con buen humor y en un ambiente de energías positivas, que motivaban espacios creativos y bienestar.

Asimismo, aprendí que toda producción toma su tiempo y que mientras más uno mismo se dedique a identificar cada mínimo detalle, mejor saldrán las cosas.

Comprendí lo importante que es para un director tener clara su visión y compartirla con el equipo. Todo el grupo tiene que estar sintonía y trabajar bajo una misma consigna. Además, me di cuenta que un director siempre tiene que guardar la calma y darle confianza y seguridad a su equipo.

Finalmente, aprendí sobre el compromiso que tiene el director con cada una de sus áreas y, como cada área se compromete con la historia. Mi equipo humano estuvo comprometido de principio a fin. Todos se movilizaba al servicio de la historia. Y ver eso me llenó de satisfacción. Saber que hay un grupo de audiovisuales talentosos y de buen corazón.

Los que quedan ha dejado en mí el deseo de seguir realizando producciones audiovisuales que dejen su granito de arena para cambiar el mundo. Sobretodo, en estas épocas cuando el mundo necesita más de historias, de esas que ayudan a escaparnos por un momento de nuestra realidad y nos permitan soñar, ya sea con un esperado reencuentro o con un baile agarrados de la mano, como el de Graciela y Chabela. 


\section{REFERENCIAS}

\section{Referencias}

Bedoya, R., \& Frías, I. L. (2003). Ojos bien abiertos. Lima: Fondo Editorial Universidad de Lima.

Bordwell, D., \& Thompson, K. (2003). Arte cinematográfico. Barcelona: Paidós.

Chion, M. (1990). El cine y sus oficios. París: Bordas.

INEI. (2018). Adultos mayores de 70 y más años de edad, que viven solos. Lima.

Martin, M. (1995). El lenguaje del cine. Paris: Les Éditions du CERF.

Martínez Salanova, E. (2003). El valor de cine para aprender y enseñar. Comunicar, 1.

Muzur, A. (2011). Ética y Cine: identificación y formación moral. Aesthethika, 8 - 19.

Sánchez-Escalonilla, A. (2016). Del guion a la pantalla. 48.

Sincero, S. M. (10 de Mayo de 2011). Explorable. Obtenido de Explorable: https://explorable.com/es/condicionamiento-operante

\section{Películas mencionadas:}

Ménégoz, M., Katz, M., Heiduschka,V. Arndt, S. (productores) y Haneke, M. (director). (2012) Amour [Película]. Austria, Francia, Alemania: X-Filme Creative Pool, Wega Film, France 3 cinéma, ARD degeto, Bayerischer Rundfunk, Westdeutscher Rundfunk,Canal+ y France télévisions.

Valladares, M., Lombardi, J. (productores) y Lombardi, J. (Dirección). (2012).

Casadentro [Película]. Perú: El Arbol Azul / Tondero Films.

Dávila, D. (productor) y Espinal, J. M. (Dirección). (2014). Hálito de Vida [Película]. Perú: Comadreja Producciones. 


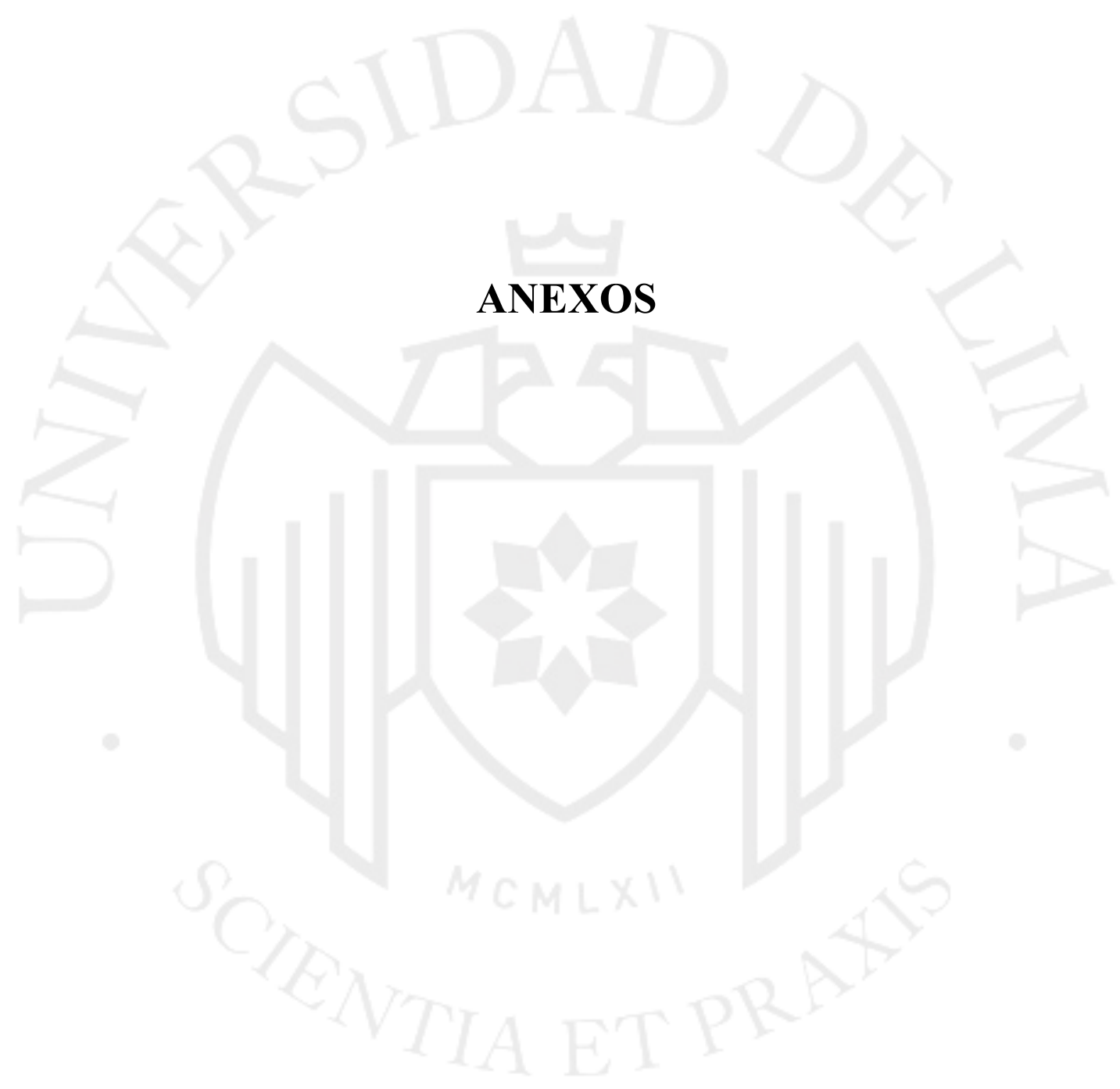




\title{
ANEXO 1: Guion
}

\author{
1. INT. CUARTO DE GRACIELA. TARDE
}

Graciela (70) despierta en su cama con el rostro cansado. Se sienta en la cama. Se limpia los ojos y se pone los lentes que los coge de su mesita de noche. Se sienta. Empieza a observar toda la habitación que la rodea, los cuadros de las paredes, el reloj colgado, y se ve a ella misma en el espejo de su tocador. Trata de sonreir, y luego se arrepiente. Se acomoda la almohada y se echa de nuevo. Se saca los lentes, los limpia y se los coloca de nuevo. Se sienta de nuevo. Abre un cajón de su mesita de noche y saca un álbum de fotos. Lo comienza a ver y se pone triste. Escucha que se acerca Chabela (35). Cierra el álbum y lo guarda. Se limpia la cara y espera en silencio. Entra Chabela con un delantal y vestida de uniforme. Lleva un plato de sopa en sus manos.

\section{CHABELA \\ Hora del almuerzo, señora Graciela.}

Graciela no dice una sola palabra. Chabela se acomoda para darle de comer. Chabela coge una cucharada de sopa y se lo da a Graciela. Graciela mira directamente a Chabela, mientras recibe cucharadas de sopa. A la tercera cucharada, Graciela deja de recibir y cierra su boca.

CHABELA

Señora, Graciela, abra la boca.

Graciela mueve su cabeza en negación.

\section{CHABELA}

Señora, mire que la sopa está bien

rica. El doctor ha dicho...

\section{GRACIELA}

(interrumpe)

Quiero que me ayudes a fingir mi muerte.

Chabela deja la cuchara en el plato.

\section{CHABELA}

Ay señora, iqué cosas dice! Ahora abra su boca y almuerce, por favor.

Graciela no abre su boca y vuelve a mover su cabeza en negación.

GRACIELA

Quiero que me ayudes a fingir mi muerte.

\section{CHABELA}

Señora, se da cuenta de lo que me está diciendo. Yo no puedo hacer eso

\section{GRACIELA}

Ya pues, Chabelita. 
CHABELA

No, se imagina lo mucho que sufririan sus hijos. Además, sería bien raro. Al menos uno de ellos sospecharía.

\section{GRACIELA}

Ni cuenta se darían... Mira, Chabelita, ite acuerdas que hace un años fuimos al velorio de Alberto? $Y$ sabes quién era Alberto, mi primer enamorado de la secundaria. Después de terminar con él nunca lo volví a ver en mi vida, pero como se murió, allí bien presentita tenía que estar. Lo mismo pasó con Virginia, la suegra de Andrea. A esa mujer la vi solo una vez en mi vida... Y se murió. Pobre si decía que tenía algo que hacer o que estaba cansada ese día. Tenía que ir a su velorio, de todas maneras.

\section{CHABELA}

Ay, señora pero no por eso usted va a querer fingir su muerte.

\section{GRACIELA}

Estoy segura que Amelia tomaría el primer vuelo desde España, a Andrea no le importaría ni un comino el trabajo ese de su esposo y vería a mi nieto... Ya estará jovencito, no? Y bueno, Alfredo, por fin vería a mi Alfredo.

\section{CHABELA}

Ay Señora no se ponga así...

GRACIELA

Por eso tienes que ayudarme.

CHABELA

No puedo hacer eso, ni loca. Además, ¿Qué pasaría si quieren ver el cajón? ¿No ha pensado en eso, acaso?

\section{GRACIELA}

Si lo he pensado. Diríamos, bueno, tú dirías que mi último deseo fue no ser vista cadáver. Lo deben respetar.

CHABELA

Señora, ¿es consciente de lo que está pidiendo, no?

GRACIELA

Sí, chabelita. Además un poco de sufrimiento no les vendría mal a los ingratos esos. 


\section{CHABELA}

Señora, no. Nada de sufrimientos. Sus hijos la quieren mucho.

GRACIELA

Si me quisieran vendrían a

visitarme... Si estuviera muerta todos

vendrían. Estoy tan segura.

CHABELA

Ay señora... No diga eso que ahorita Diosito la escucha y se me la lleva de verdacito.

\section{GRACIELA \\ (se rie)}

Chabelita, poco me falta...

CHABELA

Más poco le va a faltar si no come.

Chabela le da de comer y Graciela está vez sí recibe la comida.

\section{GRACIELA}

Chabelita, pónme esa radio que tanto me gusta. Tengo ganas de escuchar música.

\section{CHABELA}

Ya señora, todo para que se quite esos pensamientos horribles de la cabeza. Dios la perdone.

Chabela deja el plato de sopa en el tocador y acerca la radio a la cama. Busca el dial de la radio y sube el volumen. Suena una canción de antaño. Graciela escucha y cierra los ojos esbozando una sonrisa. Graciela se para de la cama con dificultad.

CHABELA

¿Qué está haciendo señora?

GRACIELA

Quiero bailar, Chabelita.

CHABELA

Pero señora Graciela, el doctor le ha pedido descanso absoluto...

GRACIELA

Chabelita, el descanso absoluto 10 tendré cuando me muera. Ven, baila conmigo.

Graciela se apoya en Chabela para pararse.

CHABELA

Está bien, señora Graciela. Bailemos. 
Ambas empiezan a moverse con lentitud.

GRACIELA

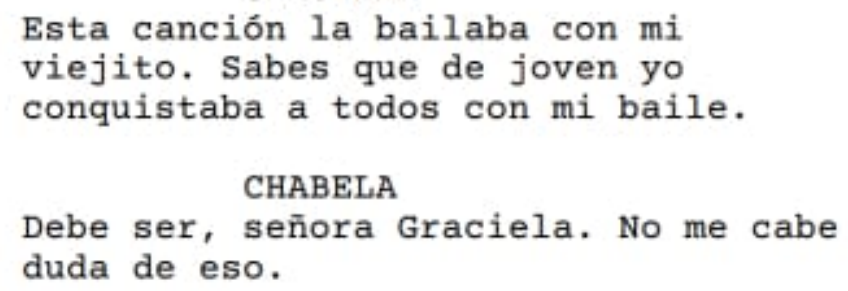

Graciela y Chabela bailan. Se muestra una foto de Graciela.

\section{INT. SALA DE COMEDOR. TARDE}

El centro de la habitación lo ocupa una mesa larga de madera. Alfredo (34), Amelia (38) y Andrea (42) están sentados alrededor de la mesa. Los tres están vestidos de negro. En el centro de la mesa está la foto de Graciela, la misma que vimos en la escena anterior. Amelia trata de disimular el llanto, mira al vacío, se seca una lágrima de las mejilla. Andrea está esperando con serenidad, tiene la cara seria, observando la escena alrededor. Alfredo muestra impaciencia moviendo los dedos en la mesa, jugando con una cajetilla de cigarros. Suena el timbre. Los tres prestan atención. Amelia se recompone, se limpia la cara; Andrea presta atención a la llegada; Alfredo deja la cajetilla de cigarro en la mesa y espera. Entra en el comedor un hombre en terno, lleva un maletín negro.

\section{JUAN CARLOS}

Buenas tardes, señores... lamento

haber demorado, el tráfico es fatal y

más en días como estos...

Los tres hermanos están en silencio observando al abogado. Juan Carlos se acomoda en la silla.

\section{JUAN CARLOS}

Bueno... a lo que vine. Como ya saben lamento mucho la pérdida de su madre, todos en la firma estamos muy apenado. Graciela fue un gran señora...
ALFREDO
(10 interrumpe)
A lo que ibas... Juan Carlos.

Amelia mira a Alfredo con desaprobación. Andrea mantiene la seriedad.

\section{JUAN CARLOS}

Si... a lo que iba. Bueno, como ustedes saben hasta el momento, se sabe que su madre no dejó nada por escrito... un 


$$
\text { testamento como tal. }
$$

2A. INT. COCINA. TARDE

Chabela tiene un rostro desencajado. Desde la cocina escucha con atención todo lo que se habla en el comedor. Mientras tanto, prepara café y coloca algunos bocaditos en un plato. Entreabre un cajón de la cocina y se queda viendo una caja que está con llave.

2. INT. SALA COMEDOR. TARDE

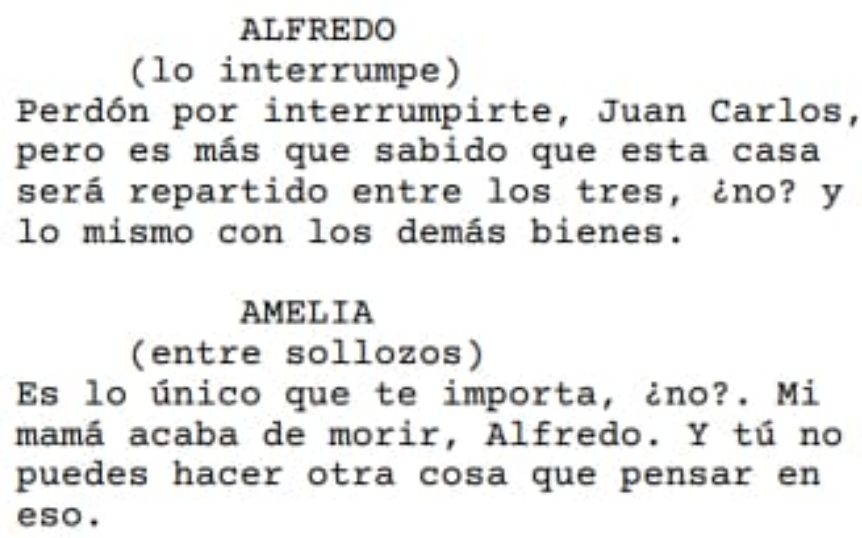

2A. INT. COCINA. TARDE

Chabela coge la caja del cajón con determinación y se dispone a salir al comedor.

2. INT. SALA COMEDOR. TARDE

Chabela interrumpe la reunión con la caja en la mano.

ANDREA

¿Qué pasó, Chabela? ¿Todo bien?

\section{ALFREDO}

Estamos en una reunión importante, Chabela. 


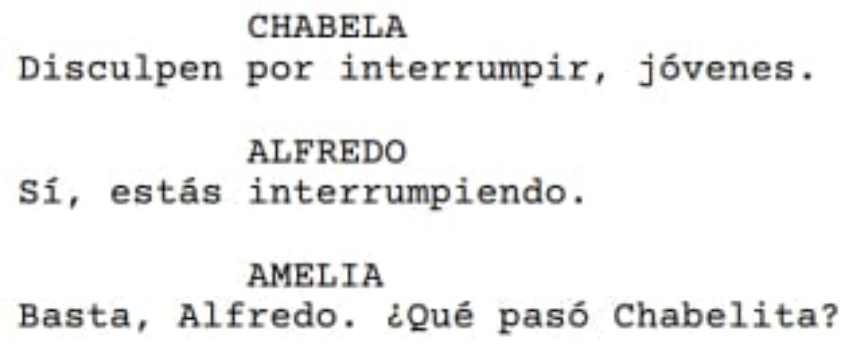

CHABELA

Me dijo que entregara esta caja justo en este momento, que no le dijera a nadie de su existencia antes de su muerte. Me dijo también que la caja solo se podía abrir con la cadena que la señorita Amelia lleva en su cuello desde su primera comunión.

Chabela mira la cadena de Amelia. Amelia acaricia su cadena.

\section{CHABELA}

Su mamasita sabia en el fondo que aún

la seguiría llevando. Es que no sabes

lo feliz que se puso cuando se la regalé, decía.

\section{JUAN CARLOS \\ (interesado)}

¿Qué más dijo? Puede continuar, por favor.

\section{CHABELA}

Me dijo que lo que estaba alli era muy importante. No me dijo que era... Solo que era importante. Cumplo con entregárselo, señor.

Chabela deja la caja con mucho cuidado en el centro de la mesa junto a la foto de Graciela.

AMELIA

Gracias, Chabelita.

ANDREA

Ya puedes retirarte, Chabela, gracias. 


\title{
ALFREDO
}

Si es posible, traes cafecito, porfa

AMELIA

iAlfredo!

\section{CHABELA}

Alli les traigo café a todos, con permiso.

Chabela sale del comedor a la cocina. Los tres hermanos y Juan Carlos observan la caja unos minutos, están entre sorprendidos e interesados, hasta que Juan Carlos la coge de la mesa.

\section{JUAN CARLOS}

Amelia me permites tu collar.

\section{AMELIA}

Sí, claro.

Amelia se quita el collar. Juan Carlos abre la caja. Adentro hay muchas fotos de sus hijos de diferentes edades. Un sobre cerrado. Juan Carlos abre el sobre con cuidado. Saca un hoja. Evidencia la firma y sello de un notario.

\author{
JUAN CARLOS \\ (sorprendido) \\ Muchachos, al parecer su madre sí dejó \\ testamento.
}

Amelia, Alfredo y Andrea se sorprenden. Juan Carlos comienza a leer.

JUAN CARLOS

"Querido hijos...

TRANSICIÓN

\section{B INT. CUARTO DE GRACIELA. TARDE}

Se ve Graciela viendo fotos de sus hijos, preparando la cajita y comenzando a escribir la carta.

\section{GRACIELA \\ (voz en off)}

"...mi amada Andrea, mi sensible Amelia y mi entrañable Alfredo: Espero que estén los tres reunidos ahora, que no falte ninguno. iHabrian hecho muy feliz a su madre si hubieran estado así de reunidos conmigo! Si esto se está leyendo, claramente es porque ya no estoy alli. Les cuento que los extraño y los he extrañado cada segundo de estos últimos días, meses y contigo Alfredo, años. Este tiempo en cama me ha hecho pensar en qué hice mal con ustedes. ¿En qué me equivoqué como madre? $\mathrm{Si}$ es que algo no salió como esperaban, les pido perdón. Escribo también este testamento, recordando que les di lo suficiente para que se valieran por ustedes mismos. Así que he decidido hacer la repartición de mis 
bienes pensando, o mejor dicho, no pensando en ustedes. Desde hace un mes, vengo haciendo una lista del tiempo que cada persona dedica para hablarme, visitarme, leerme el periódico o simplemente mirarme. De acuerdo a eso haré mi testamento.

Se ve a Graciela conversando con Pedrito (28), un joven panadero de contextura gruesa, carismático y divertido. Se ve a Pedrito entregando un pan a Graciela, riendo con ella.

\section{GRACIELA \\ (Voz en off)}

1. El panadero: de 5 a 10 minutos al día. Me traía el pan más rico que he comido en años. Siempre me preguntaba cómo estaba. A ti, Pedrito, el local de Miraflores, para que a abras una nueva panadería, la que tanto querías.

Se ve a Graciela hablando muy contenta con Rosita (38), su vecina. Rosita la hace probar distintos anillos de oro, aretes, joyas.

\section{GRACIELA \\ (Voz en off)}

2. La vecina: de 2 a 3 horitas cada dos días. Dependía siempre de la cantidad de chismes o como ella decía sucesos inesperados e importante que eran dignos de contar. A ti Rosita, todas mis joyas de oro, las que siempre decias que me quedaban bonito.

Se ve a claudita (23), una joven enfermera, acomodando la almohada de Graciela, arropando sus pies.

$$
\text { (Voz en off) }
$$

3. La enfermera: de 5 a 6 horas semanales. Un ángel de persona. Una paciencia increíble. A ti, claudita, te dejo mi cuenta bancaria de ahorros. Para que hagas la maestría que tanto querías hacer.

Se ve a Chabelita riéndose con Graciela, dándole de comer, abrazándose, bailando.

\section{GRACIELA \\ (Voz en off)}

4. Mi mejor amiga: 5 largos años de su vida. A ti, Chabelita, te dejo esta casa, que más parecía tuya que mía. Supiste darle vida cuando todo estaba muerto. Sobretodo a mí, las alegrias, las ganas de vivir y esta amistad incomparable, siempre las llevaré en mi corazón. Mantén esta casa linda como lo has estado haciendo todo este tiempo. Es tu hogar ahora. No olvides de poner esa canción que bailábamos todos los días. Recuerdame siempre, Chabelita, yo no dejaré de hacerlo.

Se ve a Graciela escribiendo y doblando la carta, guardandola en un sobre. 


\section{GRACIELA \\ (Voz en off)}

Ruego por favor que mis últimos deseos se cumplan. Y ustedes, hijos, perdonen si este testamento no fue lo que esperaban. Tantas horas en cama, me pusieron creativa. Solo espero que sean felices y encuentren lo que quizá yo nunca pude darles: la satisfacción de tener una vida en base a logros y sacrificios.

FUNDIDO A

2. INT. SALA DE DE COMEDOR. TARDE

\section{JUAN CARLOS \\ Firma: Graciela Benavides"}

El abogado deja de leer la carta. Los hijos muestran cara de desconcierto.

2A. INT. COCINA. TARDE

Las lágrimas caen por el rostro de Chabela, ella está mirando al vacío.

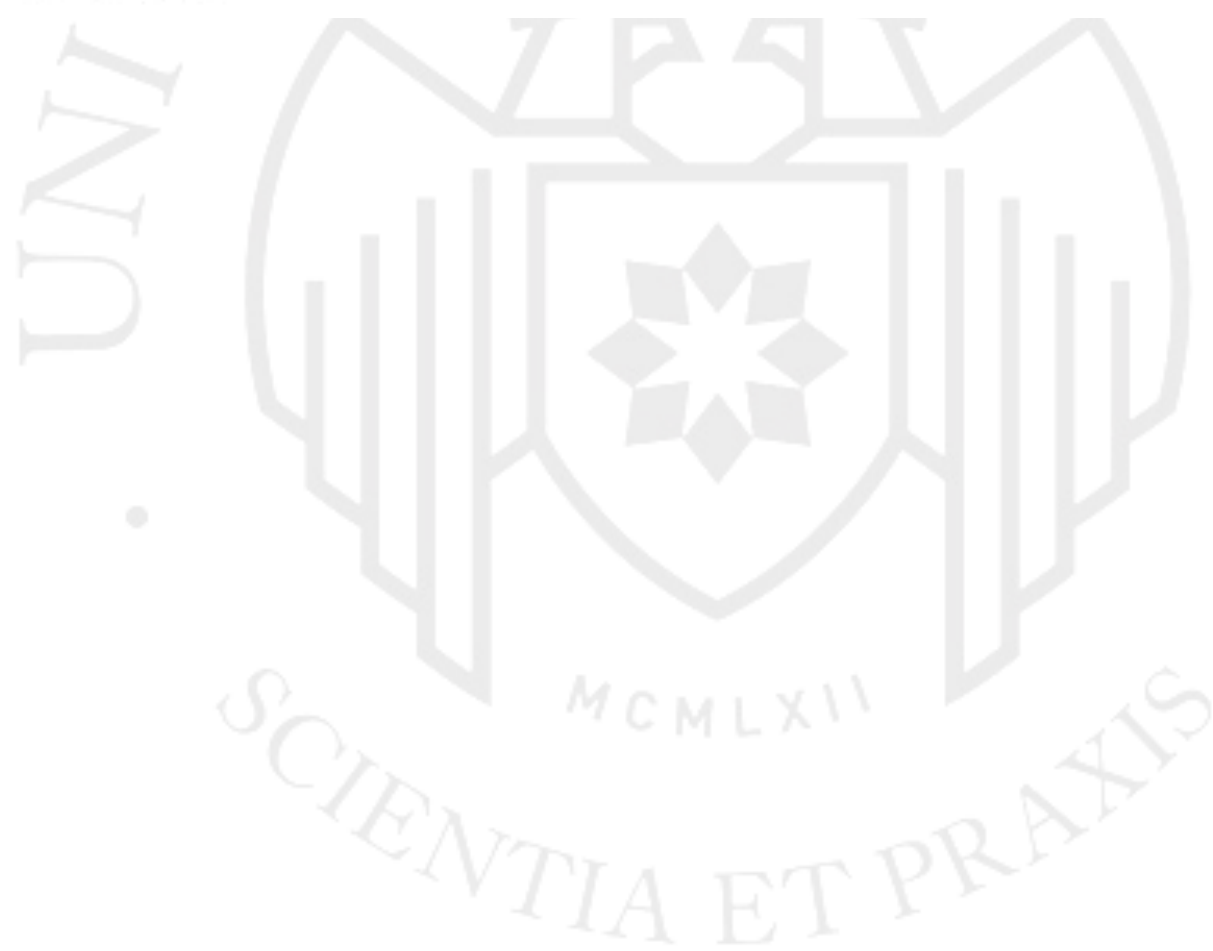




\section{ANEXO 2: Propuesta de sonido}

\begin{tabular}{|c|c|}
\hline Escena & Sonidos \\
\hline Escena 1 & $\begin{array}{l}\text { - Foleys de pasos cuando entra Chabela } \\
\text { - } \text { Diálogos en primer plano siempre, ya que es lo más importante de la } \\
\text { - Ambientes silenciosos, para dar un atmósfera de soledad } \\
\text { - La canción es una guaracha antigua. La música se pondrá en } \\
\text { postproducción. } \\
\text { - El sonido de una radio antigua (efecto de radio) }\end{array}$ \\
\hline Escena 2 & $\begin{array}{l}\text { - Ambiente silencioso, de espera } \\
\text { - Efectos de la cajetilla golpeando } \\
\text { - Diálogos en primer plano }\end{array}$ \\
\hline $\begin{array}{l}\text { Escena } \\
2 \mathrm{~A}\end{array}$ & $\begin{array}{l}\text { - Ambiental de interiores } \\
\text { - Foleys de cocina } \\
\text { - Voz en off del abogado e hijos hablando en la cocina }\end{array}$ \\
\hline $\begin{array}{l}\text { Escena } \\
2 \mathrm{~B}\end{array}$ & $\begin{array}{ll} & \text { Voz en off } \\
\text { - } & \text { Música suave y lenta }\end{array}$ \\
\hline
\end{tabular}




\section{ANEXO 3: Guion técnico}

Día 1 - Sábado 18

\begin{tabular}{|c|c|c|c|c|c|c|c|}
\hline Escena & Plano & $\begin{array}{c}\text { Encuadre/ } \\
\text { Movimiento }\end{array}$ & Acción & Texto & Sonido & $\begin{array}{l}\text { Tiempo de } \\
\text { plano }\end{array}$ & Lente \\
\hline 1 & 1 & $\begin{array}{l}\text { Plano general, del } \\
\text { baño al cuarto }\end{array}$ & $\begin{array}{c}\text { Graciela } \\
\text { durmiendo }\end{array}$ & - & Ambiental & $15 \mathrm{~s}$ & $24 \mathrm{~mm}$ \\
\hline 1 & 2 & $\begin{array}{l}\text { Plano busto de } \\
\text { Graciela desde una } \\
\text { mesita de noche. }\end{array}$ & $\begin{array}{c}\text { Graciela } \\
\text { coge sus } \\
\text { lentes. }\end{array}$ & - & Ambiental & $20 \mathrm{a}$ & $35 \mathrm{~mm}$ \\
\hline 1 & 3 & $\begin{array}{c}\text { Plano que comienza } \\
\text { en busto. Travelling } \\
\text { out y termina en } \\
\text { General }\end{array}$ & $\begin{array}{c}\text { Graciela } \\
\text { limpia los } \\
\text { lentes y se } \\
\text { los pone. } \\
\text { Graciela } \\
\text { mira su } \\
\text { cuarto, en } \\
\text { soledad. }\end{array}$ & - & Ambiental & $10 \mathrm{~s}$ & $35 \mathrm{~mm}$ \\
\hline 1 & 2 & $\begin{array}{l}\text { Plano busto de } \\
\text { Graciela desde una } \\
\text { mesita de noche }\end{array}$ & $\begin{array}{c}\text { Graciela } \\
\text { coge su } \\
\text { álbum y lo } \\
\text { mira } \\
\end{array}$ & - & Ambiental & $15 \mathrm{~s}$ & $35 \mathrm{~mm}$ \\
\hline 1 & 4 & $\begin{array}{l}\text { Plano busto de } \\
\text { Chabela desde una } \\
\text { mesita de noche }\end{array}$ & $\begin{array}{c}\text { Graciela se } \\
\text { pone triste. } \\
\text { Escucha que } \\
\text { viene } \\
\text { Chabela y } \\
\text { reacciona }\end{array}$ & - & $\begin{array}{l}\text { Ambiental. } \\
\text { Pasos de } \\
\text { Graciela }\end{array}$ & $10 \mathrm{~s}$ & $35 \mathrm{~mm}$ \\
\hline 1 & 5 & $\begin{array}{l}\text { Plano General desde } \\
\text { una esquina cerca al } \\
\text { baño }\end{array}$ & $\begin{array}{l}\text { Graciela } \\
\text { guarda el } \\
\text { álbum y } \\
\text { espera a que } \\
\text { llegue } \\
\text { Graciela. } \\
\text { Llega } \\
\text { Chabela, se } \\
\text { sienta en la } \\
\text { falda de la } \\
\text { cama }\end{array}$ & $\begin{array}{l} \\
\text { Chabela: } \\
\text { "Hora de } \\
\text { comer, } \\
\text { señora } \\
\text { Graciela" }\end{array}$ & $\begin{array}{l}\text { Ambiental, } \\
\text { diálogos. }\end{array}$ & $15 \mathrm{~s}$ & $24,35 \mathrm{~mm}$ \\
\hline 1 & 6 & $\begin{array}{c}\text { Plano conjunto de } \\
\text { ambas. Contraluz. De } \\
\text { un lado de la cama }\end{array}$ & $\begin{array}{c}\text { Chabela le da } \\
\text { de comer a } \\
\text { Graciela }\end{array}$ & & $\begin{array}{l}\text { Ambiental, } \\
\text { diálogos. }\end{array}$ & $10 \mathrm{~s}$ & $35 \mathrm{~mm}$ \\
\hline 1 & 7 & $\begin{array}{c}\text { Plano busto de } \\
\text { Graciela, con } \\
\text { referencia a Chabela }\end{array}$ & $\begin{array}{c}\text { Graciela } \\
\text { mira con } \\
\text { intensidad a } \\
\text { Chabela y } \\
\text { deja de } \\
\text { comer } \\
\end{array}$ & & $\begin{array}{l}\text { Ambiental, } \\
\text { diálogos }\end{array}$ & $3 \mathrm{~min}$ & $85 \mathrm{~mm}$ \\
\hline 1 & 8 & $\begin{array}{c}\text { Plano busto de } \\
\text { Chabela, con } \\
\text { referencia a Graciela }\end{array}$ & $\begin{array}{l}\text { Chabela } \\
\text { habla }\end{array}$ & $\begin{array}{c}\text { Chabela: } \\
\text { "Señora } \\
\text { Graciela abra } \\
\text { la boca" }\end{array}$ & $\begin{array}{l}\text { Ambiental, } \\
\text { diálogos }\end{array}$ & $10 \mathrm{~s}$ & $35 \mathrm{~mm}$ \\
\hline
\end{tabular}




\begin{tabular}{|c|c|c|c|c|c|c|c|}
\hline 1 & 9 & Detalle de la radio & $\begin{array}{c}\text { Chabela } \\
\text { buscando el } \\
\text { dial de la } \\
\text { radio }\end{array}$ & & $\begin{array}{l}\text { Ambiental, } \\
\text { sonido de } \\
\text { radio }\end{array}$ & $15 \mathrm{~s}$ & $\begin{array}{c}35 \text { o } 50 \\
\mathrm{~mm}\end{array}$ \\
\hline 1 & 10 & $\begin{array}{c}\text { Plano medio de } \\
\text { Chabela, con } \\
\text { referencia a Graciela }\end{array}$ & $\begin{array}{c}\text { Chabela } \\
\text { evitando que } \\
\text { Graciela se } \\
\text { pare }\end{array}$ & $\begin{array}{l}\text { Chabela: } \\
\text { ¿Qué esta } \\
\text { haciendo } \\
\text { señora? }\end{array}$ & $\begin{array}{l}\text { Ambiental, } \\
\text { sonido de } \\
\text { radio, diálogo }\end{array}$ & $10 \mathrm{~s}$ & $35 \mathrm{~mm}$ \\
\hline 1 & 11 & $\begin{array}{l}\text { Plano medio de } \\
\text { Graciela, con } \\
\text { referencia a Chabela }\end{array}$ & $\begin{array}{c}\text { Graciela } \\
\text { parandose }\end{array}$ & $\begin{array}{c}\text { Graciela: } \\
\text { Quiero bailar } \\
\text { chabelita }\end{array}$ & $\begin{array}{l}\text { Ambiental, } \\
\text { sonido de } \\
\text { radio, diálogo }\end{array}$ & $10 \mathrm{~s}$ & $35 \mathrm{~mm}$ \\
\hline 1 & 12 & $\begin{array}{l}\text { Plano detalle de la } \\
\text { mano de Chabela, } \\
\text { ayudando a Graciela }\end{array}$ & $\begin{array}{c}\text { Chabela y } \\
\text { Graciela } \\
\text { caminando a } \\
\text { una parte del } \\
\text { cuarto para } \\
\text { bailar }\end{array}$ & & $\begin{array}{l}\text { Ambiental, } \\
\text { sonido de } \\
\text { radio }\end{array}$ & $10 \mathrm{~s}$ & $\begin{array}{c}35 \text { o } 50 \\
\mathrm{~mm}\end{array}$ \\
\hline 1 & 13 & $\begin{array}{c}\text { Plano general de } \\
\text { Chabela y Graciela, } \\
\text { hay travelling hasta la } \\
\text { foto (ronin) }\end{array}$ & $\begin{array}{c}\text { Chabela y } \\
\text { Graciela } \\
\text { bailando, la } \\
\text { cámara se } \\
\text { mueve hasta } \\
\text { la foto. }\end{array}$ & & $\begin{array}{l}\text { Ambiental, } \\
\text { sonido de } \\
\text { radio }\end{array}$ & & $35 \mathrm{~mm}$ \\
\hline $2 \mathrm{~B}$ & 1 & $\begin{array}{c}\text { Plano detalle de sus } \\
\text { manos indecisas y } \\
\text { comenzando a } \\
\text { escribir }\end{array}$ & & & Voz en off & $10 \mathrm{~s}$ & \\
\hline $2 \mathrm{~B}$ & 2 & $\begin{array}{c}\text { Plano busto de } \\
\text { Graciela en segundo } \\
\text { termina la hoja y el } \\
\text { lapicero }\end{array}$ & $\begin{array}{c}\text { Chabela } \\
\text { cogiendo la } \\
\text { hoja y } \\
\text { empezando a } \\
\text { escribir } \\
\end{array}$ & & Voz en off & $10 \mathrm{~s}$ & 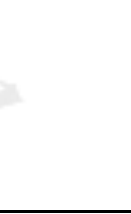 \\
\hline $2 \mathrm{~B}$ & 3 & $\begin{array}{c}\text { Plano general que } \\
\text { termina en busto, con } \\
\text { travelling in }\end{array}$ & $\begin{array}{c}\text { Chabela } \\
\text { escribiendo }\end{array}$ & & Voz en off & $10 \mathrm{~s}$ & \\
\hline
\end{tabular}

Día 2-Domingo 19

\begin{tabular}{|c|c|c|c|c|c|c|}
\hline Escena & Plano & $\begin{array}{c}\text { Encuadre/ } \\
\text { Movimiento }\end{array}$ & Acción & Texto & Sonido & Lente \\
\hline 2 & 1 & $\begin{array}{c}\text { Plano detalle de la } \\
\text { foto. Cámara en } \\
\text { movimiento hasta } \\
\text { convertirse en un } \\
\text { plano más abierto }\end{array}$ & $\begin{array}{c}\text { Amamá, camina con la } \\
\text { foto hasta la mesa y la } \\
\text { coloca allí. Vemos en } \\
\text { segundo término a } \\
\text { Alfredo sentado en el } \\
\text { comedor y a Andrea } \\
\text { leyendo una revista en } \\
\text { la sala }\end{array}$ & $24 \mathrm{~mm}$ \\
\hline 2 & 2 & $\begin{array}{c}\text { Plano general del } \\
\text { comedor. Estático }\end{array}$ & $\begin{array}{c}\text { Alfredo reacciona al } \\
\text { timbre. Alfredo sale } \\
\text { del encuadre, Amelia }\end{array}$ & $\begin{array}{c}\text { Alfredo: Yo voy. Juan } \\
\text { Carlos: Buenas tardes, } \\
\text { señores... hay trafico }\end{array}$ & $\begin{array}{c}\text { Suena el } \\
\text { timbre. } \\
\text { Diálogo }\end{array}$ & $24 \mathrm{~mm}$ \\
\hline
\end{tabular}




\begin{tabular}{|c|c|c|c|c|c|c|}
\hline & & & $\begin{array}{l}\text { se acomoda en el } \\
\text { comedor y Andrea } \\
\text { también. El plano } \\
\text { continúa hasta que } \\
\text { entra Juan Carlos y se } \\
\text { sienta en la mesa }\end{array}$ & fatal estos días & & \\
\hline 2 & 3 & $\begin{array}{l}\text { Plano busto, con } \\
\text { referencia dos hijos } \\
\text { sentados entre } \\
\text { Amelia y Andrea } \\
\text { frente al abogado }\end{array}$ & Juan Carlos se sienta & $\begin{array}{l}\text { Juan Carlos: lamento } \\
\text { mucha la perdida }\end{array}$ & Diálogo & $85 \mathrm{~mm}$ \\
\hline 2 & 4 & $\begin{array}{c}\text { Plano conjunto de } \\
\text { dos hijos. Cámara } \\
\text { al costado del } \\
\text { abogado }\end{array}$ & $\begin{array}{c}\text { Andrea y Alfredo están } \\
\text { observando a Juan } \\
\text { Carlos }\end{array}$ & $\begin{array}{c}\text { Juan Carlos: } \\
\text { Bueno.... lo que vine. }\end{array}$ & Diálogo & $35 \mathrm{~mm}$ \\
\hline 2 & 3 & \begin{tabular}{|l} 
\\
Plano busto, con \\
referencia dos hijos \\
sentados entre \\
Amelia y Andrea \\
frente al abogado
\end{tabular} & Juan Carlos se sienta & \begin{tabular}{|} 
Juan Carlos: Como ya \\
saben \\
lamento mucho la \\
pérdida de su madre, \\
todos en la firma \\
estamos muy \\
apenados. \\
Graciela fue un gran \\
señora... \\
\end{tabular} & Diálogo & $85 \mathrm{~mm}$ \\
\hline 2 & 4 & $\begin{array}{l}\text { Plano cojunto de } \\
\text { dos hijos. Cámara } \\
\text { al costado del } \\
\text { abogado }\end{array}$ & $\begin{array}{c}\text { Andrea y Alfredo están } \\
\text { observando a Juan } \\
\text { Carlos }\end{array}$ & $\begin{array}{c}\text { Alfredo: a lo que ibas, } \\
\text { Juan Carlos }\end{array}$ & Diálogo & $35 \mathrm{~mm}$ \\
\hline 2 & 5 & $\begin{array}{c}\text { Plano medio de } \\
\text { Amelia. Al costado } \\
\text { del abogado }\end{array}$ & $\begin{array}{l}\text { Amelia mirnado al } \\
\text { alfredo }\end{array}$ & $\begin{array}{c}\text { Juan Carlos: Sí... a lo } \\
\text { que iba. Bueno, como } \\
\text { ustedes saben }\end{array}$ & Diálogo & $\begin{array}{c}35 \text { o } 50 \\
\mathrm{~mm}\end{array}$ \\
\hline 2 & 4 & $\begin{array}{l}\text { Plano cojunto de } \\
\text { los dos hijos. } \\
\text { Cámara al costado } \\
\text { del abogado }\end{array}$ & $\begin{array}{l}\text { Alfredo observa a } \\
\text { Amelia }\end{array}$ & $\begin{array}{c}\text { Juan Carlos (en off): } \\
\text { hasta el momento, se } \\
\text { sabe que su madre no } \\
\text { dejó nada por escrito } \\
\text { un testamento como } \\
\text { tal }\end{array}$ & $\begin{array}{l}\text { Diálogo en } \\
\text { off, sonido de } \\
\text { tazas, } \\
\text { preparando } \\
\text { bocaditos }\end{array}$ & $35 \mathrm{~mm}$ \\
\hline $2 \mathrm{~A}$ & 1 & $\begin{array}{c}\text { Plano frontal busto } \\
\text { de Chabela, desde } \\
\text { afuera de la cocina }\end{array}$ & $\begin{array}{c}\text { Chabela escucha lo que } \\
\text { dicen en la cocina, } \\
\text { mientras perapa café y } \\
\text { Bocaditos }\end{array}$ & $\begin{array}{c}\text { Juan Carlos (en off): } \\
\text { hasta el momento, se } \\
\text { sabe que su madre no } \\
\text { dejó nada por escrito } \\
\text { un testamento como } \\
\text { tal } \\
\end{array}$ & $\begin{array}{l}\text { Diálogo desde } \\
\text { afuera de la } \\
\text { cocina y } \\
\text { sonidos de } \\
\text { cocina en off }\end{array}$ & $24 \mathrm{~mm}$ \\
\hline $2 \mathrm{~A}$ & 2 & $\begin{array}{c}\text { Plano lateral. } \\
\text { Desnfoque en el } \\
\text { objeto y objeto } \\
\text { enfocado }\end{array}$ & $\begin{array}{c}\text { Desenfocamos el } \\
\text { objeto y los enfocamos }\end{array}$ & $\begin{array}{c}\text { Juan Carlos (en off): } \\
\text { hasta el momento, se } \\
\text { sabe que su madre no } \\
\text { dejó nada por escrito } \\
\text { un testamento como } \\
\text { tal }\end{array}$ & $\begin{array}{l}\text { Diálogo desde } \\
\text { afuera de la } \\
\text { cocina y } \\
\text { sonidos de } \\
\text { cocina en off }\end{array}$ & 35 о 24 \\
\hline $2 \mathrm{~A}$ & 3 & $\begin{array}{l}\text { Plano detalle del } \\
\text { Objeto }\end{array}$ & Caja en la cocina & $\begin{array}{c}\text { "Juan Carlos (en off): } \\
\text { hasta el momento, se } \\
\text { sabe que su madre no } \\
\text { dejó nada por escrito } \\
\text { un testamento como } \\
\text { tal" } \\
\end{array}$ & $\begin{array}{l}\text { Diálogo desde } \\
\text { afuera de la } \\
\text { cocina y } \\
\text { sonidos de } \\
\text { cocina en off }\end{array}$ & 24 o 35 \\
\hline 2 & 6 & $\begin{array}{c}\text { Plano general } \\
\text { desde una esquiña }\end{array}$ & $\begin{array}{c}\text { Alfredo interrumple al } \\
\text { abogado }\end{array}$ & $\begin{array}{c}\text { Alfredo: Pero } \\
\text { obviamnete esta casa }\end{array}$ & Dialogo & 24 \\
\hline
\end{tabular}




\begin{tabular}{|c|c|c|c|c|c|c|}
\hline & & del comedor & & pasar a a nosotros & & \\
\hline 2 & 5 & $\begin{array}{l}\text { Plano medio de } \\
\text { Amelia }\end{array}$ & Amelia habla & $\begin{array}{c}\text { AMELIA } \\
\text { (entre sollozos) } \\
\text { Es lo único que te } \\
\text { importa, ¿no?. Mi } \\
\text { mamá acaba de morir, } \\
\text { Alfredo. Y tú no } \\
\text { puedes hacer otra } \\
\text { cosa que pensar en } \\
\text { eso. }\end{array}$ & Diálogos & $\begin{array}{c}35 \mathrm{~mm} \mathrm{o} \\
50 \mathrm{~mm}\end{array}$ \\
\hline 2 & 6 & $\begin{array}{c}\text { Plano general } \\
\text { desde una esquiña } \\
\text { del comedor }\end{array}$ & $\begin{array}{l}\text { Andrea los calma } \\
\text { ambos }\end{array}$ & $\begin{array}{c}\text { ANDREA (seria) Ya, } \\
\text { no peleen. ¿Y qué se } \\
\text { haría en esos casos, } \\
\text { Juan Carlos? }\end{array}$ & Diálogos & $24 \mathrm{~mm}$ \\
\hline 2 & 5 & $\begin{array}{c}\text { Plano medio de } \\
\text { Amelia }\end{array}$ & Amelia reacciona & $\begin{array}{l}\text { JUAN CARLOS } \\
\text { Sí, la casa pasaría } \\
\text { directo a ustedes, } \\
\text { se la repartirán de } \\
\text { manera equitativa, } \\
\text { evidentemente. }\end{array}$ & Diálogos & \\
\hline 2 & 4 & $\begin{array}{l}\text { Plano cojunto de } \\
\text { los dos hijos. } \\
\text { Cámara al costado } \\
\text { del abogado }\end{array}$ & Alfredo habla & $\begin{array}{c}\text { Juan Carlos: de } \\
\text { manera equitativa, } \\
\text { evidentemente. } \\
\text { Alfredo: Como debe } \\
\text { ser }\end{array}$ & Diálogos & \\
\hline 2 & 5 & $\begin{array}{c}\text { Plano medio de } \\
\text { Amelia }\end{array}$ & Amelia habla & $\begin{array}{l}\text { AMELIA: Basta } \\
\text { Allfredo }\end{array}$ & Diálogos & \\
\hline $2 \mathrm{~A}$ & 1 & $\begin{array}{l}\text { Plano frontal busto } \\
\text { de Chabela, desde } \\
\text { afuera de la cocina }\end{array}$ & $\begin{array}{l}\text { Chabela mira la caja, } \\
\text { mientras escucha lo } \\
\text { que sucede en el } \\
\text { comedor }\end{array}$ & - & En off & \\
\hline $2 \mathrm{~A}$ & 2 & $\begin{array}{c}\text { Plano detalle de la } \\
\text { caja }\end{array}$ & Chabela coge la caja & - & en off & \\
\hline $2 \mathrm{~A}$ & 3 & $\begin{array}{l}\text { Plano frontal busto } \\
\text { de Chabela, desde } \\
\text { afuera de la cocina }\end{array}$ & $\begin{array}{c}\text { Chabela sale del } \\
\text { encuadre y se dirige a } \\
\text { la cocina }\end{array}$ & - & en off & \\
\hline 2 & 2.1 & $\begin{array}{l}\text { Plano General del } \\
\text { comedor. Estático }\end{array}$ & $\begin{array}{l}\text { Chabela entra con la } \\
\text { caja en la mano se } \\
\text { dirije al centro del } \\
\text { comedor. }\end{array}$ & - & Ambiental & \\
\hline 2 & 7 & $\begin{array}{l}\text { Plano conjunto de } \\
\text { los hijos con } \\
\text { referencia a } \\
\text { Chabela }\end{array}$ & $\begin{array}{c}\text { Andrea y Alfredo } \\
\text { hablando }\end{array}$ & $\begin{array}{c}\text { ANDREA: ¿Qué } \\
\text { pasó, Chabela? ¿Todo } \\
\text { bien? } \\
\text { ALFREDO: Estamos } \\
\text { en una reunión } \\
\text { importante, } \\
\text { Chabela. }\end{array}$ & $\begin{array}{l}\text { Ambiental y } \\
\text { diálogo }\end{array}$ & $35 \mathrm{~mm}$ \\
\hline 2 & 8 & $\begin{array}{c}\text { Contraplano de } \\
\text { chabela }\end{array}$ & Chabela habla & $\begin{array}{c}\text { CHABELA: } \\
\text { Disculpen por } \\
\text { interrumpir, jóvenes. } \\
\text { ALFREDO: Sí, estás } \\
\text { interrumpiendo. } \\
\text { AMELIA: Basta, } \\
\text { Alfredo. ¿Qué pasó }\end{array}$ & $\begin{array}{l}\text { Ambiental y } \\
\text { diálogo }\end{array}$ & $35 \mathrm{~mm}$ \\
\hline
\end{tabular}




\begin{tabular}{|c|c|c|c|c|c|c|}
\hline & & & & Chabelita? & & \\
\hline 2 & 9 & $\begin{array}{c}\text { Plano medio } \\
\text { frontal de Chabela. } \\
\text { Travelling in lento } \\
\text { (pedir slider) }\end{array}$ & $\begin{array}{l}\text { Ella hablando. Hace } \\
\text { una ligera pausa para } \\
\text { mirar al abogado. }\end{array}$ & $\begin{array}{c}\text { Chabela: Antes de } \\
\text { morir la señora } \\
\text { Graciela me } \\
\text { dio algunas órdenes } \\
\text { explícitas. Juan } \\
\text { Carlos: ¿Qué le dijo? } \\
\text { ¿Qué le dijo? }\end{array}$ & $\begin{array}{c}\text { Ambiental y } \\
\text { diálogo }\end{array}$ & $\begin{array}{c}35 \text { o } 50 \\
\mathrm{~mm}\end{array}$ \\
\hline 2 & 10 & $\begin{array}{c}\text { Plano medio de } \\
\text { Amelia. Al costado } \\
\text { del abogado }\end{array}$ & $\begin{array}{l}\text { Amelia cogiendo su } \\
\text { cadena, mientras que } \\
\text { escucha a Graciela y } \\
\text { mira al abogado } \\
\text { cuando interrumpe }\end{array}$ & $\begin{array}{l}\text { CHABELA (en off) } \\
\text { Su mamasita sabía en } \\
\text { el fondo que aún } \\
\text { la seguiría llevando. } \\
\text { Es que no sabes } \\
\text { lo feliz que se puso } \\
\text { cuando se la } \\
\text { regalé, decía. } \\
\text { JUAN CARLOS } \\
\text { (interesado) } \\
\text { ¿Qué más dijo? Puede } \\
\text { continuar, por } \\
\text { favor. }\end{array}$ & $\begin{array}{c}\text { Ambiental y } \\
\text { diálogo }\end{array}$ & $50 \mathrm{~mm}$ \\
\hline 2 & 9 & $\begin{array}{l}\text { Plano medio } \\
\text { frontal de Chabela. } \\
\text { Travellin in (slider) }\end{array}$ & $\begin{array}{l}\text { Chabela dejando la } \\
\text { caja en la mesa y } \\
\text { saliendo del encuadre }\end{array}$ & $\begin{array}{l}\text { Es que no sabes } \\
\text { lo feliz que se puso } \\
\text { cuando se la } \\
\text { regalé, decía. } \\
\text { CHABELA } \\
\text { Me dijo que lo que } \\
\text { estaba allí era muy } \\
\text { importante. No me } \\
\text { dijo que era... Solo } \\
\text { que era importante. } \\
\text { Cumplo con } \\
\text { entregárselo, señor. }\end{array}$ & $\begin{array}{c}\text { Ambiental y } \\
\text { diálogo }\end{array}$ & $50 \mathrm{~mm}$ \\
\hline 2 & 10 & $\begin{array}{c}\text { Plano medio de } \\
\text { Amelia. Al costado } \\
\text { del abogado. Baja } \\
\text { hasta coger la caja. } \\
\text { Desnfoque y } \\
\text { enfoque }\end{array}$ & Chabela deja la caja. & $\begin{array}{c}\text { AMELIA } \\
\text { Gracias, Chabelita }\end{array}$ & $\begin{array}{c}\text { Ambiental y } \\
\text { diálogo }\end{array}$ & $\begin{array}{c}85 \text { o } 50 \\
\mathrm{~mm}\end{array}$ \\
\hline 2 & 6.1 & $\begin{array}{c}\text { Plano general } \\
\text { desde una esquiña } \\
\text { del comedor }\end{array}$ & $\begin{array}{l}\text { Amelia, Andrea y } \\
\text { Alfredo despidiendo a } \\
\text { Chabela. Ven la caja } \\
\text { por un rato hasta que } \\
\text { Juan Carlos coge la } \\
\text { caja }\end{array}$ & $\begin{array}{c}\text { ANDREA } \\
\text { Ya puedes retirarte, } \\
\text { Chabela, gracias. } \\
\text { ALFREDO } \\
\text { Si puedes hazme un } \\
\text { cafecito, pues. } \\
\text { AMELIA } \\
\text { iAlfredo! } \\
\text { CHABELA } \\
\text { Allí les traigo café, } \\
\text { con permiso. }\end{array}$ & $\begin{array}{c}\text { Ambiental y } \\
\text { diálogo }\end{array}$ & \\
\hline
\end{tabular}




\begin{tabular}{|c|c|c|c|c|c|c|}
\hline 2 & 3.1 & \begin{tabular}{|} 
Plano busto, con \\
referencia dos hijos \\
sentados entre \\
Amelia y Andrea \\
frente al abogado. \\
Referencia hombro \\
de Amelia \\
sacandose el collar
\end{tabular} & $\begin{array}{c}\text { Juan Carlos cogiendo } \\
\text { la caja, Amelia } \\
\text { empezando a dar el } \\
\text { collar }\end{array}$ & $\begin{array}{c}\text { JUAN CARLOS } \\
\text { Amelia me permites } \\
\text { tu collar. }\end{array}$ & $\begin{array}{c}\text { Ambiental y } \\
\text { diálogo }\end{array}$ & \\
\hline 2 & 11 & \begin{tabular}{|c|} 
Plano conjunto. \\
Enfoque y \\
desenfoque del \\
collar con Alfredo. \\
Desde una esquina \\
del comedor \\
\end{tabular} & $\begin{array}{l}\text { Amelia dandole el } \\
\text { collar }\end{array}$ & $\begin{array}{l}\text { AMELIA } \\
\text { Sí, claro. }\end{array}$ & $\begin{array}{c}\text { Ambiental y } \\
\text { diálogo }\end{array}$ & $85 \mathrm{~mm}$ \\
\hline 2 & 12 & $\begin{array}{c}\text { Plano que } \\
\text { comienza conjunto } \\
\text { (ronin) Camara se } \\
\text { mueve hasta } \\
\text { terminar en } \\
\text { oversoulder y } \\
\text { convertirse en } \\
\text { plano detalle }\end{array}$ & La caja abriendo & $\begin{array}{l}\text { Juan carlo: Al parecer } \\
\text { su madre si dejo } \\
\text { testamento }\end{array}$ & $\begin{array}{c}\text { Ambiental y } \\
\text { diálogo }\end{array}$ & $\begin{array}{c}34 \text { o } 24 \\
\mathrm{~mm}\end{array}$ \\
\hline 2 & 3.1 & \begin{tabular}{|c|} 
Plano busto, con \\
referencia dos hijos \\
sentados entre \\
Amelia y Andrea \\
frente al abogado.
\end{tabular} & $\begin{array}{c}\text { Juan Carlos abriendo la } \\
\text { caja }\end{array}$ & $\begin{array}{l}\text { JuanCarlos: Al } \\
\text { parecer su madre sí } \\
\text { dejó testamento }\end{array}$ & $\begin{array}{c}\text { Ambiental y } \\
\text { diálogo }\end{array}$ & \\
\hline 2 & 13 & $\begin{array}{l}\text { Plano conjunto } \\
\text { busto. desde una } \\
\text { esquina del } \\
\text { comedor }\end{array}$ & reacción de los hijos & - & Ambiental & \\
\hline 2 & 3.1 & \begin{tabular}{|} 
Plano busto, con \\
referencia dos hijos \\
sentados entre \\
Amelia y Andrea \\
frente al abogado.
\end{tabular} & $\begin{array}{c}\text { Juan Carlos abriendo la } \\
\text { caja }\end{array}$ & $\begin{array}{l}\text { Abogado: Queridos } \\
\text { hijos }\end{array}$ & $\begin{array}{c}\text { Ambiental y } \\
\text { diálogo }\end{array}$ & \\
\hline 2 & 14 & $\begin{array}{l}\text { Plano frontal del } \\
\text { aboagdo con } \\
\text { referencia de los } \\
\text { hijos. Travelling } \\
\text { out. Hasta que sea } \\
\text { plano general con } \\
\text { la escena del } \\
\text { comedor } \\
\text { desenfocada y la } \\
\text { escena de la cocina } \\
\text { en foco }\end{array}$ & $\begin{array}{l}\text { El abogado leyendo. } \\
\text { Graciela llorando en la } \\
\text { cocina }\end{array}$ & $\begin{array}{l}\text { Abogado: Firma, } \\
\text { Graciela Benavides }\end{array}$ & $\begin{array}{c}\text { Ambiental y } \\
\text { diálogo }\end{array}$ & $24 \mathrm{~mm}$ \\
\hline
\end{tabular}




\section{ANEXO 4: Storyboard}
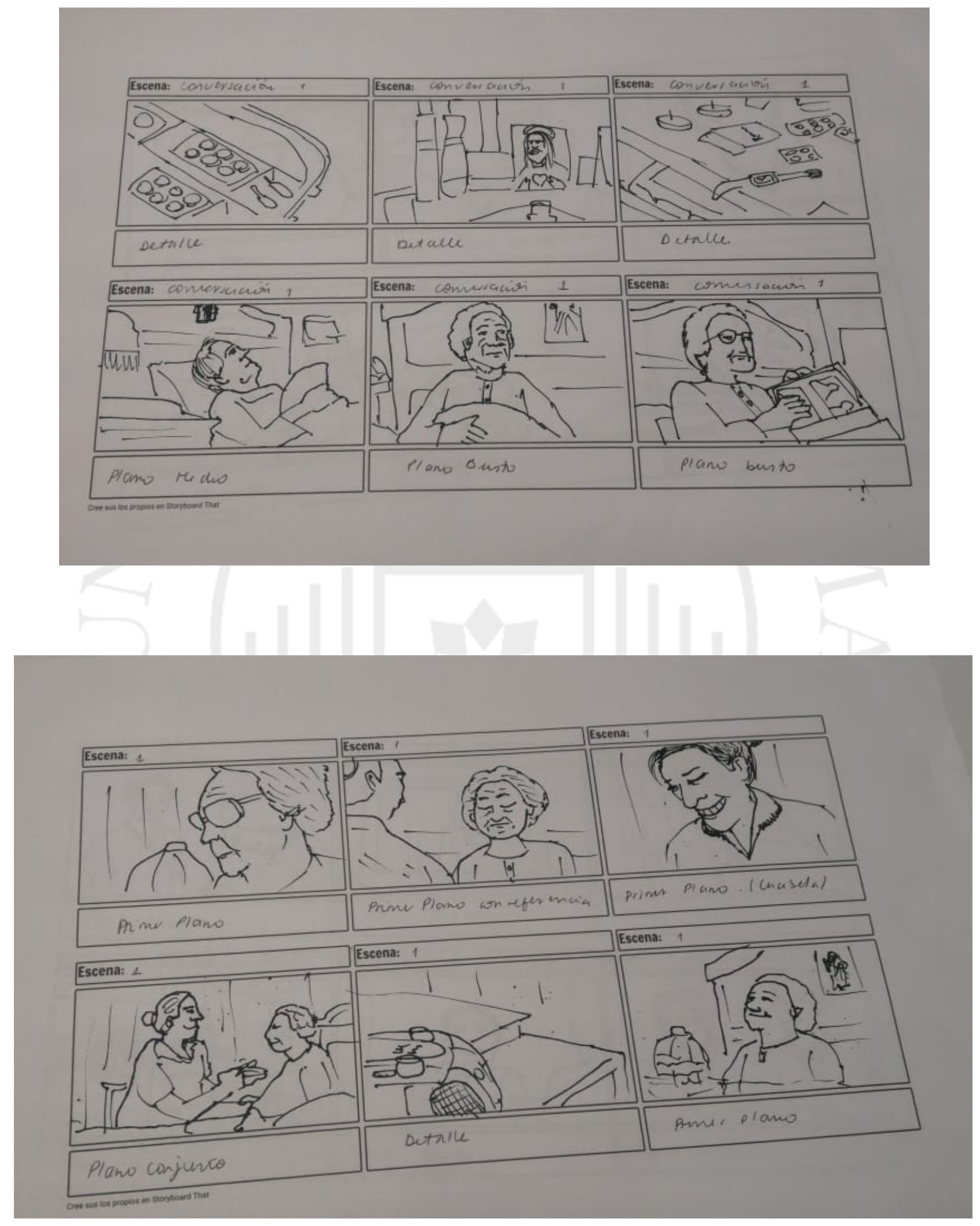


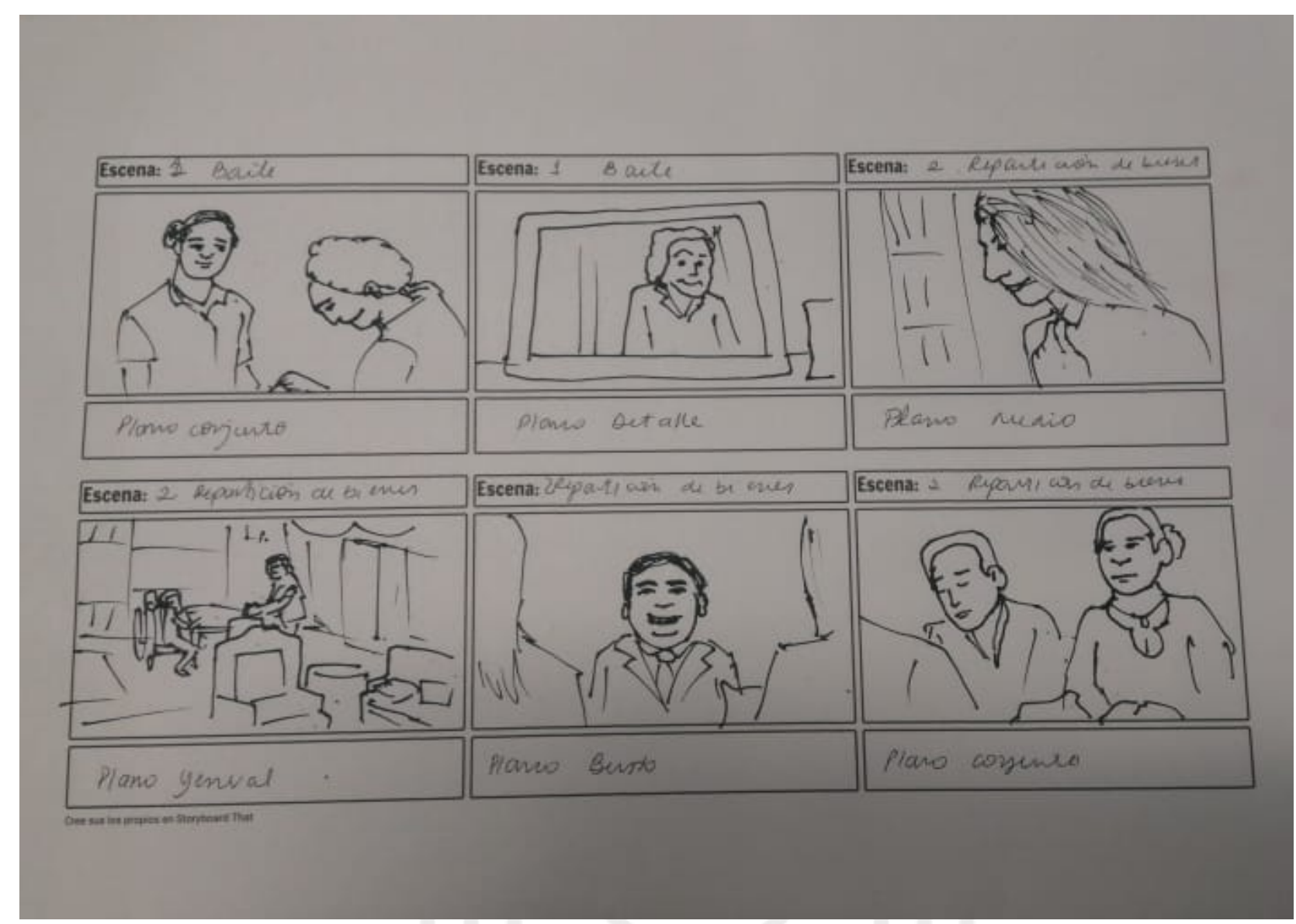




\section{ANEXO 5: Plan de rodaje}

Día 1

\begin{tabular}{|c|c|c|c|c|c|c|c|c|c|c|}
\hline \multicolumn{11}{|c|}{ SÁBADO 18 - Av. De Las Artes Norte 1499} \\
\hline Locación & Hora & Escena & Planc & & Acción & Pág. & Nota & Luz & & Lente \\
\hline \multirow[t]{8}{*}{$\begin{array}{l}\text { Cuarto } \\
\text { de } \\
\text { Graciela }\end{array}$} & 08:00 & 1 & 2 & $\begin{array}{l}\text { Busto desde mesa } \\
\text { de noche. }\end{array}$ & $\begin{array}{l}\text { Graciela } \\
\text { coge sus } \\
\text { lentes. }\end{array}$ & & & Día & INT & 35 \\
\hline & $08: 20$ & 1 & 4 & $\begin{array}{l}\text { Busto, desde mesa } \\
\text { de noche }\end{array}$ & $\begin{array}{l}\text { Graciela se } \\
\text { pone triste. } \\
\text { Escucha que } \\
\text { viene } \\
\text { Graciela y } \\
\text { reacciona. }\end{array}$ & & & Día & INT & 35 \\
\hline & $08: 40$ & 1 & 3 & $\begin{array}{l}\text { Travelling out, } \\
\text { termina en un } \\
\text { General }\end{array}$ & $\begin{array}{l}\text { Graciela } \\
\text { limpia los } \\
\text { lentes y se } \\
\text { los } \\
\text { pone.Chabela } \\
\text { mira su } \\
\text { cuarto, en } \\
\text { soledad. }\end{array}$ & & & Día & INT & 35 \\
\hline & $09: 10$ & 1 & 1 & $\begin{array}{l}\text { General, del baño al } \\
\text { cuarto }\end{array}$ & $\begin{array}{l}\text { Graciela } \\
\text { durmiendo. }\end{array}$ & & & Día & INT & 24 \\
\hline & 09:40 & 1 & 5 & $\begin{array}{l}\text { General (desde una } \\
\text { esquina cerca al } \\
\text { baño) }\end{array}$ & $\begin{array}{l}\text { Graciela } \\
\text { guarda el } \\
\text { álbum y } \\
\text { espera a que } \\
\text { llegue } \\
\text { Graciela. } \\
\text { Llega } \\
\text { Chabela, se } \\
\text { sienta en la } \\
\text { falda de la } \\
\text { cama. }\end{array}$ & & $\begin{array}{l}\text { Atención a } \\
\text { la radio } \\
\text { (tomar } \\
\text { foto). }\end{array}$ & Día & INT & $24 / 35$ \\
\hline & 10:00 & 1 & 5.1 & $\begin{array}{l}\text { General (desde una } \\
\text { esquina cerca al } \\
\text { baño) }\end{array}$ & $\begin{array}{l}\text { Chabela } \\
\text { acerca la } \\
\text { radio a } \\
\text { Graciela }\end{array}$ & & & Día & INT & \\
\hline & $10: 20$ & 1 & 6 & $\begin{array}{l}\text { Conjunto (a } \\
\text { contraluz desde el } \\
\text { lado de la cama) }\end{array}$ & $\begin{array}{l}\text { Chabela le da } \\
\text { de comer a } \\
\text { Graciela. }\end{array}$ & & & Día & INT & 35 \\
\hline & $10: 40$ & 1 & 7 & $\begin{array}{l}\text { Busto de Graciela, } \\
\text { con referencia a } \\
\text { Chabela }\end{array}$ & $\begin{array}{l}\text { Graciela mira } \\
\text { con } \\
\text { intensidad a } \\
\text { Chabela y }\end{array}$ & & & Día & INT & 85 \\
\hline
\end{tabular}




\begin{tabular}{|c|c|c|c|c|c|c|c|c|c|}
\hline & & & & & $\begin{array}{l}\text { deja de } \\
\text { comer. }\end{array}$ & & & & \\
\hline & $11: 00$ & 1 & 8 & $\begin{array}{l}\text { Busto de Chabela, } \\
\text { con referencia a } \\
\text { Graciela }\end{array}$ & $\begin{array}{l}\text { Chabela } \\
\text { habla. }\end{array}$ & & Día & INT & 35 \\
\hline & $11: 20$ & 1 & 9 & Detalle radio & $\begin{array}{l}\text { Chabela } \\
\text { buscando el } \\
\text { dial de la } \\
\text { radio. }\end{array}$ & & Día & INT & $35 / 50$ \\
\hline & $11: 40$ & 1 & 10 & $\begin{array}{l}\text { Medio de Chabela, } \\
\text { referencia a } \\
\text { Graciela. }\end{array}$ & $\begin{array}{l}\text { Chabela } \\
\text { evitando que } \\
\text { Graciela se } \\
\text { pare. }\end{array}$ & & Día & INT & 35 \\
\hline & $12: 00$ & 1 & 11 & $\begin{array}{l}\text { Medio de Graciela, } \\
\text { referencia a } \\
\text { Chabela. }\end{array}$ & $\begin{array}{l}\text { Graciela } \\
\text { parándose. }\end{array}$ & & Día & INT & 35 \\
\hline & $12: 20$ & 1 & 12 & $\begin{array}{l}\text { Detalle mano de } \\
\text { Chabela, ayudando } \\
\text { a Graciela. }\end{array}$ & $\begin{array}{l}\text { Chabela y } \\
\text { Graciela } \\
\text { caminando a } \\
\text { una parte del } \\
\text { cuarto para } \\
\text { bailar. }\end{array}$ & & Día & INT & \\
\hline & $12: 50$ & 1 & 13 & $\begin{array}{l}\text { General de Chabela } \\
\text { y } \\
\text { Graciela. Travelling } \\
\text { hasta la foto (ronin) }\end{array}$ & $\begin{array}{l}\text { Chabela y } \\
\text { Graciela } \\
\text { bailando, la } \\
\text { cámara se } \\
\text { mueve hasta } \\
\text { la foto. }\end{array}$ & & Día & INT & \\
\hline & $13: 20$ & & & & llmuerzo & & & & \\
\hline Cuarto & $14: 00$ & $2 \mathrm{~B}$ & 4 & & & & Día & INT & \\
\hline & $14: 20$ & $2 \mathrm{~B}$ & 5 & & & & Día & INT & \\
\hline Cocina & $14: 40$ & $2 \mathrm{~B}$ & 6 & & $\begin{array}{l}\text { Graciela abre } \\
\text { la puerta a } \\
\text { Panadero. }\end{array}$ & $\begin{array}{l}\text { Cambio de } \\
\text { vestuario } 2 \\
\text { (Graciela) }\end{array}$ & Día & INT & \\
\hline & $15: 00$ & $2 \mathrm{~B}$ & 7 & & $\begin{array}{l}\text { Panadero } \\
\text { entrega pan a } \\
\text { Graciela. }\end{array}$ & & Día & INT & \\
\hline & $15: 20$ & $2 \mathrm{~B}$ & 8 & & $\begin{array}{l}\text { Graciela } \\
\text { sonriendo. }\end{array}$ & $\begin{array}{l}\text { Última } \\
\text { escena con } \\
\text { Chabela }\end{array}$ & Día & INT & \\
\hline Jardín & $15: 40$ & $2 \mathrm{~B}$ & 9 & & $\begin{array}{l}\text { Vecina llega } \\
\text { a visitar el } \\
\text { jardín. }\end{array}$ & $\begin{array}{l}\text { Cambio de } \\
\text { vestuario } 3 \\
\text { (Graciela) }\end{array}$ & Día & EXT & \\
\hline
\end{tabular}




\begin{tabular}{|l|l|l|l|l|l|l|l|l|l|l|}
\hline & $16: 00$ & 2B & 10 & Detalle joyas. & $\begin{array}{l}\text { Vecina } \\
\text { admira joyas } \\
\text { de Graciela. }\end{array}$ & & Día & EXT & \\
\hline $\begin{array}{l}\text { Cuarto } \\
\text { de } \\
\text { Graciela }\end{array}$ & $16: 20$ & 2B & $\begin{array}{l}11 \\
12\end{array}$ & & $\begin{array}{l}\text { Enfermera } \\
\text { cuida a } \\
\text { Graciela con } \\
\text { dulzura. }\end{array}$ & & $\begin{array}{l}\text { Cambio de } \\
\text { vestuario 4 } \\
\text { (Graciela) }\end{array}$ & Día & INT & \\
\cline { 2 - 8 } & $\begin{array}{l}17: 00 \\
\text { a } \\
18: 00 \\
\text { máx. }\end{array}$ & 2B & 1 & 2 & $\begin{array}{l}\text { Graciela } \\
\text { escribiendo } \\
\text { la carta para } \\
\text { los hijos. }\end{array}$ & $\begin{array}{l}\text { Volver al } \\
\text { cambio de } \\
\text { vestuario } \\
\text { de la } \\
\text { escena 1 } \\
\text { para } \\
\text { Graciela. }\end{array}$ & Día & INT & & \\
\hline
\end{tabular}

DOMINGO 19 - Av. De Las Artes Norte 1499

\begin{tabular}{|c|c|c|c|c|c|c|c|c|c|c|c|}
\hline \multirow{2}{*}{$\begin{array}{l}\text { Locación } \\
\text { Comedor }\end{array}$} & \multirow{2}{*}{$\begin{array}{l}\text { Hora } \\
08: 25\end{array}$} & \multirow{2}{*}{$\begin{array}{l}\text { Escena } \\
2\end{array}$} & \multicolumn{2}{|c|}{ Plano } & \multirow{2}{*}{$\begin{array}{l}\text { Acción } \\
\text { Alfredo reacciona al } \\
\text { timbre. Alfredo sale } \\
\text { del encuadre, } \\
\text { Amelia y Andrea se } \\
\text { acomodan en el } \\
\text { comedor. El plano } \\
\text { continúa hasta que } \\
\text { entra Juan Carlos y } \\
\text { se sienta en la mesa. }\end{array}$} & \multirow{2}{*}{$\begin{array}{l}\text { Pág. } \\
4\end{array}$} & \multirow{2}{*}{$\begin{array}{l}\text { Actores } \\
\text { Amelia, } \\
\text { Alfredo } \\
\text { y } \\
\text { Andrea, } \\
\text { Juan } \\
\text { Carlos }\end{array}$} & \multirow[t]{2}{*}{ Nota } & \multicolumn{2}{|l|}{ Luz } & \multirow{2}{*}{$\begin{array}{l}\text { Lente } \\
24\end{array}$} \\
\hline & & & 2 & $\begin{array}{l}\text { General del } \\
\text { comedor. } \\
\text { Estático. }\end{array}$ & & & & & Día & INT & \\
\hline & $8: 40$ & 2 & 3 & $\begin{array}{l}\text { Busto, con } \\
\text { referencia a } \\
2 \text { hijos } \\
\text { sentados } \\
\text { entre Amelia } \\
\text { y Andrea } \\
\text { frente al } \\
\text { abogado. }\end{array}$ & $\begin{array}{l}\text { Juan Carlos se } \\
\text { sienta. }\end{array}$ & & $\begin{array}{l}\text { Amelia, } \\
\text { Alfredo } \\
\text { y } \\
\text { Andrea, } \\
\text { Juan } \\
\text { Carlos }\end{array}$ & & Día & INT & 85 \\
\hline & 9:00 & 2 & 4 & $\begin{array}{l}\text { Conjunto de } \\
\text { los hijos. } \\
\text { Cámara al } \\
\text { lado del } \\
\text { abogado }\end{array}$ & $\begin{array}{l}\text { Andrea y Alfredo } \\
\text { están observando a } \\
\text { Juan Carlos. }\end{array}$ & & $\begin{array}{l}\text { Amelia, } \\
\text { Alfredo } \\
\text { y } \\
\text { Andrea, } \\
\text { Juan } \\
\text { Carlos }\end{array}$ & & Día & INT & 35 \\
\hline & $9: 30$ & 2 & 5 & $\begin{array}{l}\text { Medio de } \\
\text { Amelia. Al } \\
\text { costado del } \\
\text { Abogado. }\end{array}$ & $\begin{array}{l}\text { Amelia mirando a } \\
\text { Alfredo. }\end{array}$ & & $\begin{array}{l}\text { Amelia, } \\
\text { Alfredo } \\
\text { y } \\
\text { Andrea, } \\
\text { Juan } \\
\text { Carlos }\end{array}$ & & Día & INT & $35 / 50$ \\
\hline & 10:00 & 2 & 6 & $\begin{array}{l}\text { General } \\
\text { desde } \\
\text { esquina del } \\
\text { comedor. }\end{array}$ & $\begin{array}{l}\text { Alfredo interrumpe } \\
\text { al Abogado. }\end{array}$ & 5 & $\begin{array}{l}\text { Amelia, } \\
\text { Alfredo } \\
\text { y } \\
\text { Andrea, }\end{array}$ & & Día & INT & 24 \\
\hline
\end{tabular}




\begin{tabular}{|c|c|c|c|c|c|c|c|c|c|}
\hline & & & & & $\begin{array}{l}\text { Juan } \\
\text { Carlos }\end{array}$ & & & & \\
\hline $10: 20$ & 2 & 3.1 & $\begin{array}{l}\text { Plano busto, } \\
\text { con } \\
\text { referencia } \\
\text { dos hijos } \\
\text { sentados } \\
\text { entre Amelia } \\
\text { y Andrea } \\
\text { frente al } \\
\text { abogado. } \\
\text { Referencia } \\
\text { hombro de } \\
\text { Amelia } \\
\text { sacandose el } \\
\text { collar. }\end{array}$ & $\begin{array}{l}\text { Juan Carlos } \\
\text { cogiendo la caja, } \\
\text { Amelia empezando } \\
\text { a dar el collar. }\end{array}$ & $\begin{array}{l}\text { Amelia, } \\
\text { Alfredo } \\
\text { y } \\
\text { Andrea, } \\
\text { Juan } \\
\text { Carlos }\end{array}$ & $\begin{array}{l}\text { Memorizar } \\
\text { cómo sale } \\
\text { la caja } \\
\text { (tomar } \\
\text { foto) }\end{array}$ & Día & INT & \\
\hline $11: 00$ & 2 & 13 & $\begin{array}{l}\text { Conjunto } \\
\text { busto. Desde } \\
\text { esquina del } \\
\text { comedor. }\end{array}$ & Reacción de hijos. & $\begin{array}{l}\text { Amelia, } \\
\text { Alfredo } \\
\text { y } \\
\text { Andrea, } \\
\text { Juan } \\
\text { Carlos }\end{array}$ & & Día & INT & \\
\hline $11: 30$ & 2 & 11 & $\begin{array}{l}\text { Conjunto. } \\
\text { Enfoque y } \\
\text { desenfoque } \\
\text { del collar } \\
\text { con Alfredo. } \\
\text { Desde } \\
\text { esquina del } \\
\text { comedor. }\end{array}$ & $\begin{array}{l}\text { Amelia dándole el } \\
\text { collar. }\end{array}$ & $\begin{array}{l}\text { Amelia, } \\
\text { Alfredo } \\
\text { y } \\
\text { Andrea, } \\
\text { Juan } \\
\text { Carlos }\end{array}$ & & Día & INT & 85 \\
\hline $12: 00$ & 2 & 12 & $\begin{array}{l}\text { Comienza } \\
\text { en conjunto } \\
\text { (ronin). } \\
\text { Cámara se } \\
\text { mueve hasta } \\
\text { terminar en } \\
\text { overshoulder } \\
\text { y convertirse } \\
\text { en plano } \\
\text { detalle. }\end{array}$ & La caja abriendo. & $\begin{array}{l}\text { Amelia, } \\
\text { Alfredo } \\
\text { y } \\
\text { Andrea, } \\
\text { Juan } \\
\text { Carlos }\end{array}$ & & Día & INT & $34 / 24$ \\
\hline $12: 30$ & 2 & 1 & $\begin{array}{l}\text { Detalle de la } \\
\text { foto. Cámara } \\
\text { en } \\
\text { movimiento } \\
\text { hasta } \\
\text { convertirse } \\
\text { en un plano } \\
\text { más abierto }\end{array}$ & $\begin{array}{l}\text { Amelia ve la foto de } \\
\text { su mamá, camina } \\
\text { con la foto hasta la } \\
\text { mesa y la coloca } \\
\text { allí. Vemos en } \\
\text { segundo término a } \\
\text { Alfredo sentado en } \\
\text { el comedor y a } \\
\text { Andrea leyendo una } \\
\text { revista en la sala. }\end{array}$ & $\begin{array}{l}\text { Amelia, } \\
\text { Alfredo } \\
\text { y } \\
\text { Andrea. }\end{array}$ & & Día & INT & 24 \\
\hline $13: 00$ & 2 & 2.1 & & $\begin{array}{l}\text { Chabela llega a la } \\
\text { mesa y corta el } \\
\text { plano. }\end{array}$ & $\begin{array}{l}\text { Amelia, } \\
\text { Alfredo } \\
\text { y }\end{array}$ & & Día & INT & \\
\hline
\end{tabular}




\begin{tabular}{|c|c|c|c|c|c|c|c|c|c|c|}
\hline & & & & & & & $\begin{array}{l}\text { Andrea, } \\
\text { Juan } \\
\text { Carlos, } \\
\text { Chabela }\end{array}$ & & & \\
\hline & & \multicolumn{9}{|c|}{ Almuerzo } \\
\hline \multirow[t]{6}{*}{ Comedor } & $14: 00$ & 2 & 7 & $\begin{array}{l}\text { Conjunto de } \\
\text { hijos con } \\
\text { referencia a } \\
\text { Chabela }\end{array}$ & $\begin{array}{l}\text { Andrea y Alfredo } \\
\text { hablando }\end{array}$ & & $\begin{array}{l}\text { Amelia, } \\
\text { Alfredo } \\
\text { y } \\
\text { Andrea, } \\
\text { Juan } \\
\text { Carlos, } \\
\text { Chabela }\end{array}$ & Día & INT & 35 \\
\hline & $14: 20$ & 2 & 8 & $\begin{array}{l}\text { Contraplano } \\
\text { de Chabela }\end{array}$ & Chabela habla. & & $\begin{array}{l}\text { Amelia, } \\
\text { Alfredo } \\
\text { y } \\
\text { Andrea, } \\
\text { Juan } \\
\text { Carlos, } \\
\text { Chabela }\end{array}$ & Día & INT & 35 \\
\hline & $14: 40$ & 2 & 9 & $\begin{array}{l}\text { Medio } \\
\text { frontal de } \\
\text { Chabela. } \\
\text { Travelling in } \\
\text { lento (slider) }\end{array}$ & $\begin{array}{l}\text { Chabela hablando. } \\
\text { Hace una ligera } \\
\text { pausa para mirar al } \\
\text { abogado. }\end{array}$ & & $\begin{array}{l}\text { Amelia, } \\
\text { Alfredo } \\
\text { y } \\
\text { Andrea, } \\
\text { Juan } \\
\text { Carlos, } \\
\text { Chabela }\end{array}$ & Día & INT & $35 / 50$ \\
\hline & $15: 00$ & 2 & 6.1 & $\begin{array}{l}\text { General } \\
\text { desde una } \\
\text { esquina del } \\
\text { comedor }\end{array}$ & $\begin{array}{l}\text { Amelia, Andrea y } \\
\text { Alfredo despidiendo } \\
\text { a Chabela. Ven la } \\
\text { caja por un rato } \\
\text { hasta que Juan } \\
\text { Carlos coge la caja. }\end{array}$ & & $\begin{array}{l}\text { Amelia, } \\
\text { Alfredo } \\
\text { y } \\
\text { Andrea, } \\
\text { Juan } \\
\text { Carlos, } \\
\text { Chabela }\end{array}$ & Día & INT & \\
\hline & $15: 20$ & 2 & 10 & $\begin{array}{l}\text { Medio de } \\
\text { Amelia. Al } \\
\text { costado del } \\
\text { abogado. }\end{array}$ & $\begin{array}{l}\text { Amelia cogiendo su } \\
\text { cadena, mientras } \\
\text { escucha a Graciela y } \\
\text { mira al abogado } \\
\text { cuando interrumpe. }\end{array}$ & & $\begin{array}{l}\text { Amelia, } \\
\text { Alfredo } \\
\text { y } \\
\text { Andrea, } \\
\text { Juan } \\
\text { Carlos, } \\
\text { Chabela }\end{array}$ & Día & INT & 50 \\
\hline & $15: 40$ & 2 & 14 & $\begin{array}{l}\text { Frontal del } \\
\text { abogado con } \\
\text { referencia de } \\
\text { los hijos. } \\
\text { Travelling } \\
\text { out. Hasta } \\
\text { que sea } \\
\text { plano } \\
\text { general con } \\
\text { la escena del } \\
\text { comedor } \\
\text { desenfocada }\end{array}$ & $\begin{array}{l}\text { Abogado leyendo. } \\
\text { Graciela llorando en } \\
\text { la cocina. }\end{array}$ & & $\begin{array}{l}\text { Amelia, } \\
\text { Alfredo } \\
\text { y } \\
\text { Andrea, } \\
\text { Juan } \\
\text { Carlos, } \\
\text { Chabela }\end{array}$ & Día & INT & 24 \\
\hline
\end{tabular}




\begin{tabular}{|c|c|c|c|c|c|c|c|}
\hline & & & $\begin{array}{l}\text { y la escena } \\
\text { de la cocina } \\
\text { en foco }\end{array}$ & & & & \\
\hline $16: 00$ & $2 \mathrm{~A}$ & 1 & $\begin{array}{l}\text { Plano frontal } \\
\text { busto de } \\
\text { Chabela, } \\
\text { desde afuera } \\
\text { de la cocina }\end{array}$ & $\begin{array}{l}\text { Chabela mira la } \\
\text { caja, mientras } \\
\text { escucha lo que } \\
\text { sucede en el } \\
\text { comedor }\end{array}$ & Chabela & Día & INT \\
\hline $16: 20$ & $2 \mathrm{~A}$ & 2 & $\begin{array}{l}\text { Plano } \\
\text { lateral. } \\
\text { Desenfoque } \\
\text { en el objeto } \\
\text { y objeto } \\
\text { enfocado }\end{array}$ & Chabela coge la caja & Chabela & Día & INT \\
\hline $16: 40$ & $2 \mathrm{~A}$ & 3 & $\begin{array}{l}\text { Plano detalle } \\
\text { del Objeto }\end{array}$ & $\begin{array}{l}\text { Chabela sale del } \\
\text { encuadre y se dirige } \\
\text { a la cocina }\end{array}$ & Chabela & Día & INT \\
\hline
\end{tabular}


ANEXO 6: Hora de llamado

\begin{tabular}{|l|l|}
\hline \multicolumn{2}{|l|}{ SÁBADO 18 - LLAMADOS } \\
\hline Hora & Tarea \\
\hline 07:00 & Llegan Arte/Luces/Cámara \\
\hline 07:20 & Pedir taxi para Delfina \\
\hline 07:30 & Recoger Delfina \\
\hline 07:40 & Llegan Delfina (Graciela)/Ana Lucía/Making off \\
\hline 08:40 & Recoger Ursula \\
\hline 09:10 & Llega Ursula (Chabela) a maquillarse. Arte atento. \\
\hline 13:00 & Poner la mesa y servir almuerzos. \\
\hline 13:55 & Cambio de vestuario de Ursula y Delfina. \\
\hline 15:40 & Llevar a Ursula (Chabela) a su casa. \\
\hline 17:45 & Llevar a Delfina (Graciela) a su casa. \\
\hline
\end{tabular}

\begin{tabular}{|l|l|}
\hline \multicolumn{2}{|l|}{ DOMINGO 19 - LLAMADOS } \\
\hline Hora & Tarea \\
\hline 07:40 & Recoger actores \\
\hline 07:25 & Arte/Luces/Cámara \\
\hline 08:00 & $\begin{array}{l}\text { Llegan Sonido } \\
\text { Oscar Belia Cárdenas } \\
\text { Abogado Chiara }\end{array}$ \\
\hline $10: 00$ & Llega Úrsula \\
\hline 13:30 & Poner la mesa y servir almuerzos. \\
\hline 15:00 & Llevar Oscar Beltrán a su casa. \\
\hline 17:00 & Llevar a Ursula (Chabela) a su casa. \\
\hline
\end{tabular}


ANEXO 7: Fotos de making of

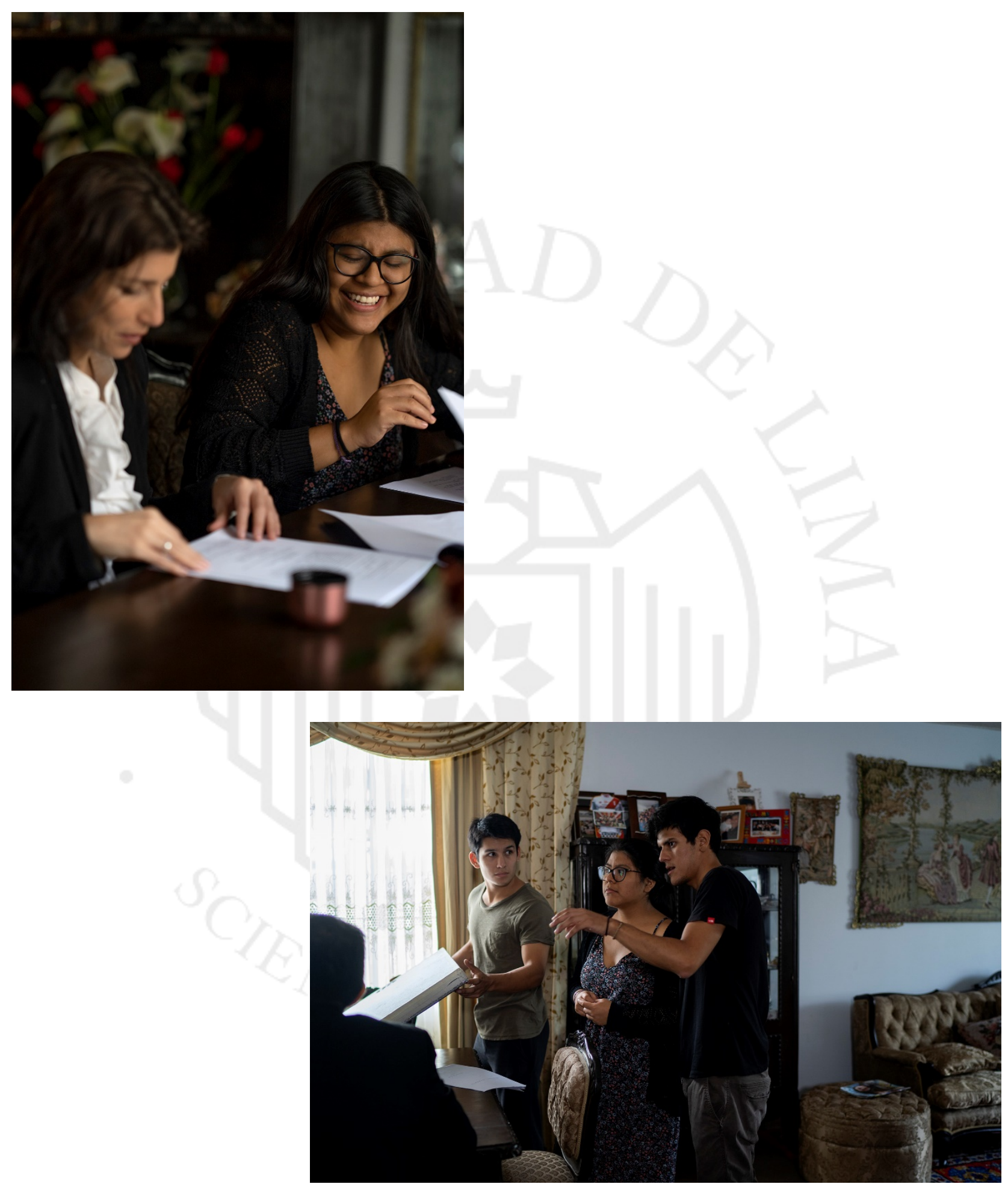



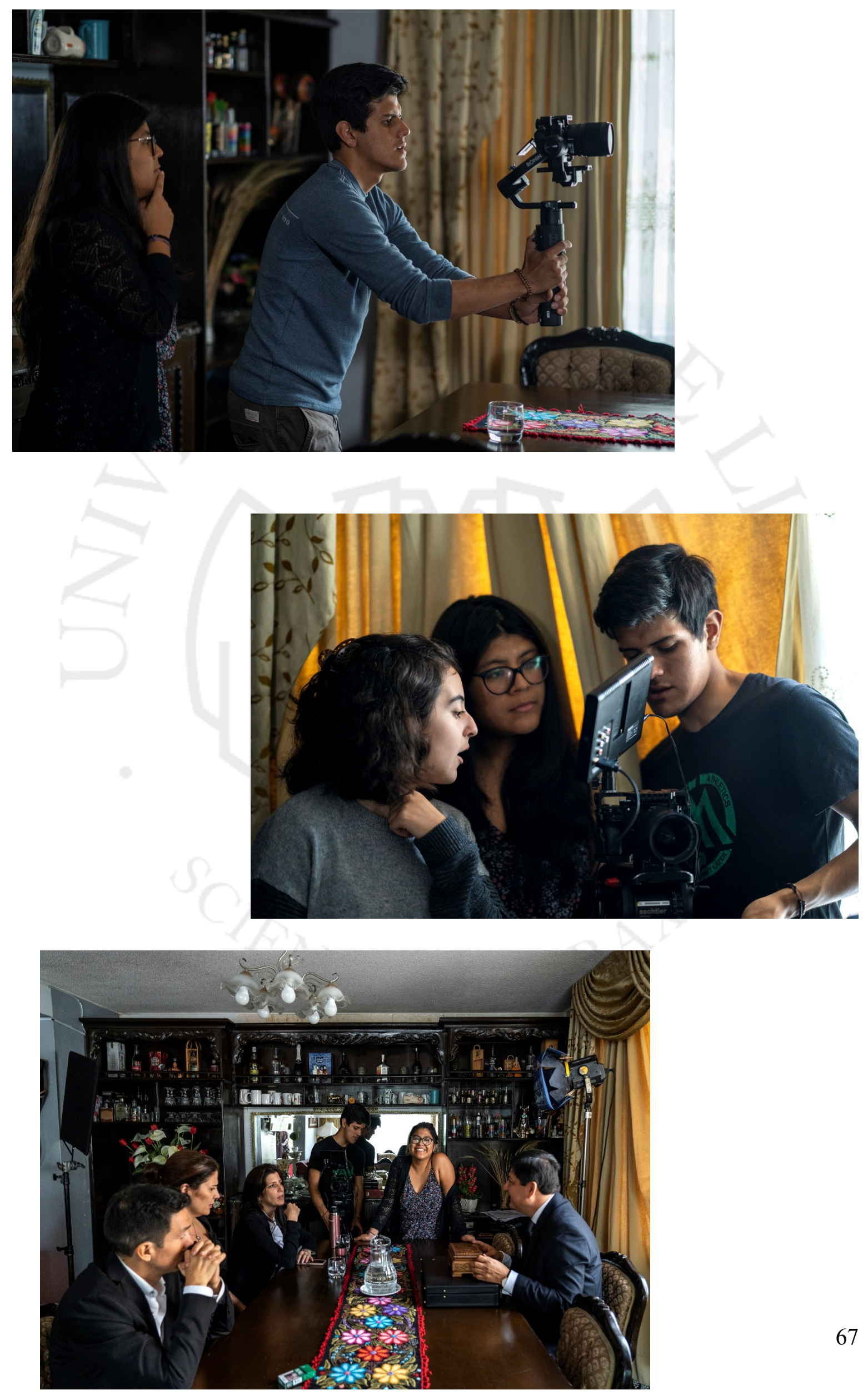


\section{ANEXO 8: Press Kit}

\section{Sinopsis en español}

Graciela es una mujer de edad avanzada que comparte sus días con Chabela, una humilde ama de casa enviada por sus hijos para cuidarla. Con la ayuda de um testamento y su gran amistad, ambas mujeres nos dejarán una gran importante lección.

\section{Ficha Artística}

\begin{tabular}{|l|l|l|}
\hline \multirow{3}{*}{ Protagonistas } & Graciela & Delfina Paredes \\
\cline { 2 - 3 } & Chabelita & Úrsula Mármol \\
\hline \multirow{5}{*}{ Secundarios } & Alfredo & Óscar Beltrán \\
\cline { 2 - 3 } & Amelia & Natalia Cárdenas \\
\cline { 2 - 3 } & Andrea & Caroll Chiara \\
\cline { 2 - 3 } & Juan Carlos & Freddy Cruzado \\
\hline \multirow{5}{*}{ Extras } & Pedro & Sergio Plaza \\
\cline { 2 - 3 } & Rosa & Esperanza Loayza \\
\cline { 2 - 3 } & Claudia & Alessandra Vera \\
\hline
\end{tabular}

Ficha Técnica

\begin{tabular}{|l|l|}
\hline Director & Karla Gómez \\
\hline Asistente de Dirección & Sergio Plaza \\
\hline Productor Ejecutivo & Esperanza Loayza \\
\hline Productor General & Alessandra Vera \\
\hline Asistente de Producción & Alejandra Ontaneda \\
\hline Segundo Asistente de Producción & Brenda Cruzado \\
\hline Guionista & Karla Gómez \\
\hline Director de Fotografía & Alejandro Serruto \\
\hline Asistente de Fotografía & Fabrizio Rivva \\
\hline Gaffer & Diego Chavez \\
\hline Luminotécnico & Nicole Sanchez \\
\hline Script & Sergio Plaza \\
\hline Dirección de Arte & Abril Ibérico \\
\hline Asistente de Arte & Alexia Gildemeister \\
\hline Dirección de Sonido & David Saurre \\
\hline Asistente de Sonido & Lia Santamaria \\
\hline Sonido directo & Ana-Lucia Moreno \\
\hline Edición & Anishell Freundt \\
\hline
\end{tabular}




\begin{tabular}{|l|l|}
\hline Colorización & Alejandro Serruto \\
\hline Mezcla de sonido & Isa Pinedo Abad \\
\hline
\end{tabular}

\section{Datos técnicos}

\begin{tabular}{|l|l|}
\hline Duración & $00: 19: 11$ \\
\hline Formato de reproducción & Full HD \\
\hline Sonido & Stereo \\
\hline Fecha de estreno & 7 de Diciembre del 2019 \\
\hline País de producción & Perú \\
\hline Lenguaje & Español \\
\hline Cámara utilizada & Sony A7sIII \\
\hline
\end{tabular}




\section{ANEXO 9: Poster}

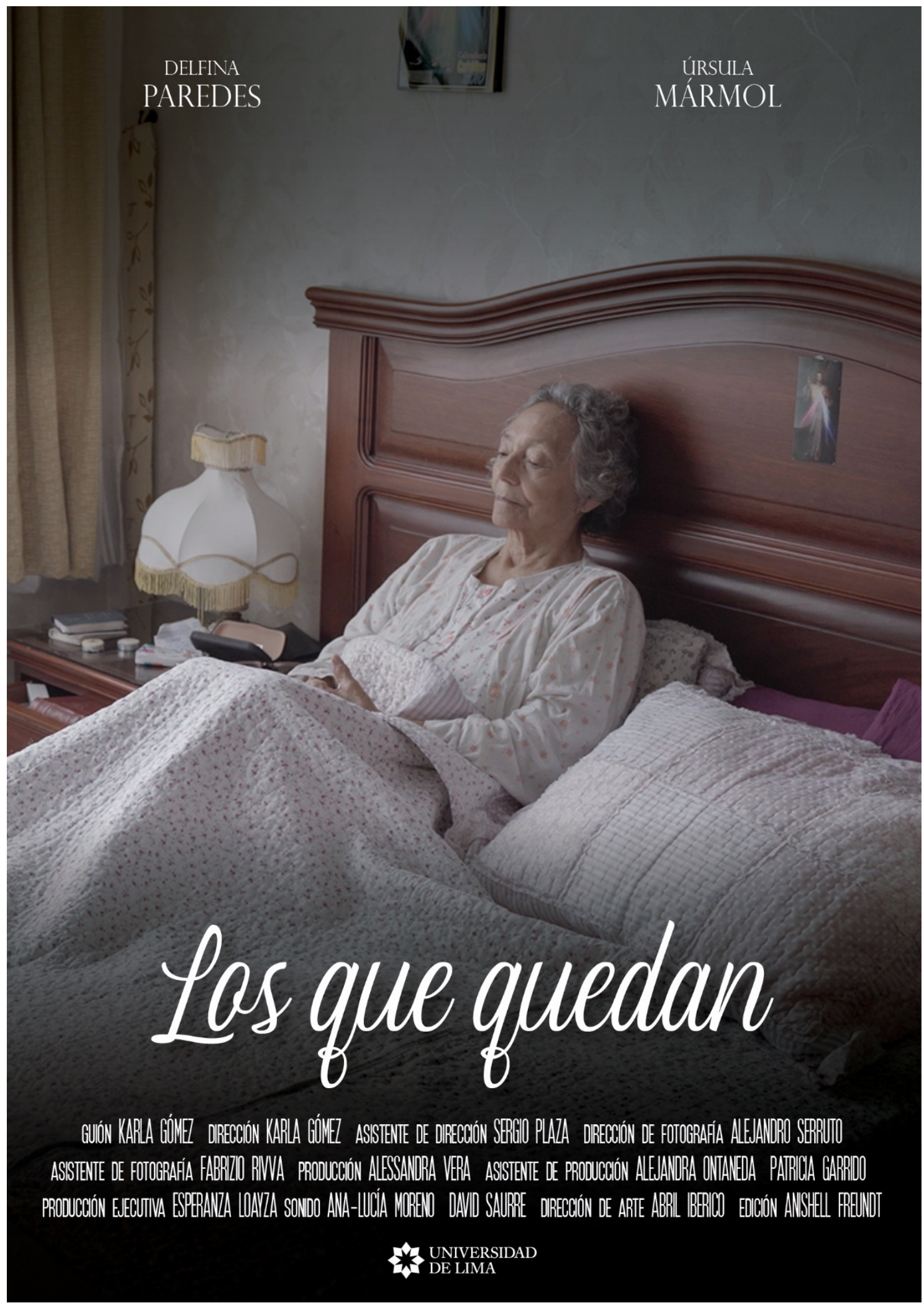

